J Med Chem. 2019 April 25; 62(8): 4131-4141. doi:10.1021/acs.jmedchem.9b00191.

\title{
Novel Lysine-Based Thioureas as Mechanism-Based Inhibitors of Sirtuin 2 (SIRT2) with Anticancer Activity in a Colorectal Cancer Murine Model
}

\author{
Ali Sohail Farooqi ${ }^{\dagger}$, Jun Young Hong ${ }^{\dagger}$, Ji Cao ${ }^{\dagger} \S$, Xuan Lu $^{\dagger}$, lan Robert Price ${ }^{\dagger}$, Qingjie \\ Zhao $^{\dagger}, \mathbb{I}$, Tatsiana Kosciuk ${ }^{\dagger}$, Min Yang ${ }^{\dagger}$, Jessica Jingyi Bai ${ }^{\dagger}$, Hening Lin ${ }^{\star}, \ddagger$ \\ tDepartment of Chemistry and Chemical Biology, Cornell University, Ithaca, New York 14853, \\ United States \\ ҒHoward Hughes Medical Institute, Department of Chemistry and Chemical Biology, Cornell \\ University, Ithaca, New York 14853, United States
}

\begin{abstract}
Sirtuin 2 (SIRT2) is a protein lysine deacylase that has been indicated as a therapeutic target for cancer. To further establish the role of SIRT2 in cancers, it is necessary to develop selective and potent inhibitors. Here, we report the facile synthesis of novel lysine derived thioureas as mechanism-based SIRT2 inhibitors with anticancer activity. Compounds AF8, AF10, and AF12 selectively inhibited SIRT2 with $\mathrm{IC}_{50}$ values of $0.06,0.15$, and $0.08 \mu \mathrm{M}$, respectively. Compounds AF8 and AF10 demonstrated broad cytotoxicity amongst cancer cell lines, but minimal toxicity in noncancerous cells. AF8 and AF10 inhibited the anchorage-independent growth of human colorectal cancer cell line $\mathrm{HCT} 116$ with $\mathrm{GI}_{50}$ values of $\sim \mu \mathrm{M}$. Furthermore, AF8 potently inhibited tumor growth in a HCT116 xenograft murine model, supporting that SIRT2 is a viable therapeutic target for colorectal cancer.
\end{abstract}

\section{Graphical Abstract}

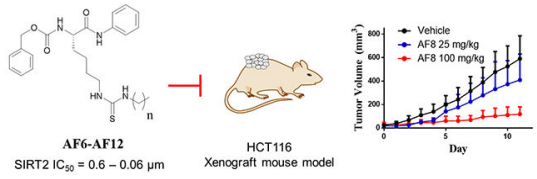

*Corresponding Author: h1379@ cornell.edu.

§resent Address: Zhejiang Province Key Laboratory of Anti-Cancer Drug Research, College of Pharmaceutical Sciences, Zhejiang University, Hangzhou, China. 310058

IPresent Address: Shanghai Institute of Materia Medica, Chinese Academy of Sciences, No. 501, Haike Rd., Pudong New District, Shanghai 201203, China.

Author Contributions

A.S.F., J.Y.H., and J.C. contributed equally to this work. The manuscript was written through contributions of all authors. All authors have given approval to the final version of the manuscript.

Supporting Information. The following files are available free of charge.

In vitro inhibition assays of SIRT1-3 with compounds AF8 - AF12, cell cytotoxicity assay of various cell lines comparing compounds AF8, AF10, and TM, and ${ }^{1} \mathrm{H}$ and ${ }^{13} \mathrm{C}$ NMR spectra of all synthesized intermediates and final compounds. (PDF) Molecular Formula Strings (CSV)

qNMR of synthesized compounds (PDF) 


\section{INTRODUCTION}

Sirtuins are a class of nicotinamide adenine dinucleotide $\left(\mathrm{NAD}^{+}\right)$dependent enzymes with lysine deacetylase activities. ${ }^{1-2}$ They are also referred to as class III histone deacetylases, but can catalyze the deacylation of various non-histone substrates. ${ }^{3}$ In mammals, there are seven sirtuins (SIRT1-7) that are involved in the regulation of cellular metabolism, transcription, and differentiation. ${ }^{4-5}$ Specifically, SIRT1, SIRT2, and SIRT5 have been implicated in promoting cancer cell proliferation and tumorigenesis. ${ }^{6-8}$ While SIRT1 and SIRT2 have also been contradictorily shown to be tumor suppressors ${ }^{7,9}$, the therapeutic potential of targeting SIRT2 has been demonstrated by isoform specific inhibition in breast cancer cell lines. ${ }^{10}$ Recently, SIRT2 was shown to promote tumor growth by regulating oncogenes $c-M y c$ and KRas. ${ }^{6,}{ }^{11}$ SIRT2 also promotes basal like breast cancer phenotype and tumor growth through the deacetylation and stabilization of transcription factor Slug. ${ }^{12}$ As such, SIRT2 regulates multiple oncogenic pathways and is a promising therapeutic target for cancer. However, there is a need for more studies in animal models of cancer to convincingly demonstrate the therapeutic potential of SIRT2 inhibition.

Several SIRT2-selective inhibitors, such as AGK2, Tenovin-6, TM, and SirReal2, have been reported. ${ }^{10,13-15}$ Among these, the thiomyristoyl lysine compound TM is a SIRT2 mechanism-based inhibitor that displayed cancer cell-selective toxicity and is active in many human cancer cell lines. ${ }^{10,16}$ The sirtuin deacylation mechanism involves nucleophilic attack on the $\mathrm{NAD}^{+}$anomeric position by the carbonyl of the acyl group to release nicotinamide (Scheme 1) ${ }^{17}$ TM contains a thiomyristoyl lysine moiety, which can attack the anomeric position of $\mathrm{NAD}^{+}$in the presence of SIRT2, forming a stable covalent intermediate to potently inhibit SIRT2. ${ }^{10}$

While TM has promising anticancer activity, it is poorly soluble in water and the synthesis of the thioamide bond is difficult and results in poor yield. We therefore sought to develop similar mechanism-based inhibitors that are less hydrophobic and easier to synthesize. In a previous study by Hirsch, et. al, it was shown that a peptidomimetic thiourea containing compound could mechanistically inhibit SIRT1 and lead to the general inhibition of SIRT1$3 .{ }^{18}$ Modifying TM with a thiourea moiety could similarly result in improved mechanism based inhibition and facilitate a simplified synthesis route. Here, we present the development of novel lysine-based thioureas as potent and selective SIRT2 inhibitors with anticancer activity in various cancer cell lines and a colorectal cancer xenograft murine model.

\section{RESULTS AND DISCUSSION}

\section{Design and synthesis of new SIRT2 inhibitors.}

Two different classes of thiourea inhibitors with varying alkyl chain lengths were synthesized through a divergent synthesis route (Scheme 2). The $\mathbf{C}$ class of inhibitors C1-12 contained a 3' hydroxyl group on the C-terminal while the AF class of inhibitors AF6-12 did not. Modeling the inhibitors into the known SIRT2 structure suggested the 3' hydroxyl group of the $\mathbf{C}$ inhibitors could facilitate additional hydrogen bonding interactions with the backbone of residues Val266 or Gln267 (Fig. 1). ${ }^{19}$ The $\mathbf{C}$ inhibitors could therefore have improved potency and solubility as compared to the AF inhibitors. SIRT2 contains a 
hydrophobic pocket for acyl group binding ${ }^{15,20}$, and this pocket accommodates the thiomyristoyl group present in TM. Towards the goal of reducing the hydrophobicity of the inhibitors, we decided to synthesize thiourea compounds with various alkyl chain lengths.

Commercially available Cbz-L-lysine(Boc)-OH was converted to the corresponding isothiocyanate intermediates $\mathbf{2 a}$ and $\mathbf{2 b}$ in two steps with $54 \%$ and $83 \%$ yield respectively. The isothiocyanate compounds were then coupled with varying alkyl chain primary amines to form the resultant thiourea compounds, with up to 94\% yield. In total, the six C1-C12 inhibitors varied in chain length from one to twelve carbons and the five AF6-AF12 inhibitors varied from six to twelve carbons.

\section{AF8, AF10, and AF12 are potent and selective SIRT2 inhibitors in vitro.}

We then measured the ability of these compounds to inhibit SIRT1, SIRT2, and SIRT3. Because SIRT1, SIRT2, and SIRT3 are similar structurally and comprise the class I sirtuins ${ }^{21}$, it was important to test for selectivity among these three isoforms. A liquid chromatography based assay with acetyl H3K9 peptide $^{2}$ and purified sirtuins was used to test the compounds for SIRT1-3 inhibition. The previously reported TM compound was also assayed and used as a reference compound. Nicotinamide, a non-specific sirtuin inhibitor, was used as a positive control for SIRT3 inhibition and the SIRT1 selective inhibitor EX527 used as a positive control for SIRT1 inhibition. ${ }^{22-24}$ Nicotinamide weakly and non-specifically inhibited SIRT3 $\left(\mathrm{IC}_{50} 76 \pm 30 \mu \mathrm{M}\right)$ and SIRT2 ( IC $_{50} 70 \pm 5 \mu \mathrm{M}$ ) while EX527 more potently inhibited SIRT1 $\left(\right.$ IC $\left._{50} 0.085 \pm 0.01 \mu \mathrm{M}\right)$ over SIRT2 $\left(\mathrm{IC}_{50} 1.80 \pm 0.03\right.$ $\mu \mathrm{M})$, consistent with reported literature values. ${ }^{22,25}$

As shown in Table 1, none of the synthesized inhibitors demonstrated significant inhibition of SIRT3 with $\mathrm{IC}_{50}$ values of $50 \mu \mathrm{M}$ or greater. Except for inhibitors $\mathbf{C 1}$ and $\mathbf{C 3}$, all inhibitors had micromolar $(\mathbf{C 5})$ or submicromolar $\mathrm{IC}_{50}$ values for SIRT2. The lack of SIRT2 deacetylase inhibition for compounds $\mathbf{C 1}$ and $\mathbf{C 3}$ is likely due to the shorter side chains of one and three carbons, respectively, which led to decreased interactions in the sirtuin hydrophobic pocket. A trend of increased chain length and increased SIRT2 inhibition was observed, suggesting that a longer alkyl chain length facilitates increased binding in the hydrophobic pocket.

Compounds C8-C12 were potent for SIRT2 with $\mathrm{IC}_{50}$ values of $0.12 \mu \mathrm{M}$ or lower, but also inhibited SIRT1 with $\mathrm{IC}_{50}$ values of $1.0,0.45$, and $1.0 \mu \mathrm{M}$ for $\mathbf{C 8}, \mathbf{C 1 0}$, and C12, respectively. The decreased selectivity is likely because the additional hydrogen bonding capability of C8-C12 increases the SIRT1 inhibition more than the SIRT2 inhibition. The resultant 8 to 17-fold selectivity for SIRT2 over SIRT1 was not adequate to ensure SIRT2specific inhibition for biological testing. As a result, the non-selective inhibitors C8-C12 were not used in further biological activity assays.

AF6, AF7, AF8, AF10, and AF12 inhibited SIRT2 deacetylase activity with IC $_{50}$ values of $0.64,0.16,0.061,0.15$, and $0.081 \mu \mathrm{M}$ respectively (Table 1). AF8 slightly inhibited SIRT1 deacetylase activity $\left(\mathrm{IC}_{50} 11 \pm 5 \mu \mathrm{M}\right)$ while AF10, AF12, and TM showed no inhibition. The inhibition of SIRT3 was weakest and only AF8 showed slight inhibition of SIRT3. The selectivity for SIRT2 over SIRT1 correlated with the alkyl chain length of the inhibitors, as 
demonstrated by the 47, 137, 180, >1000, and >1000-fold selectivity of AF6, AF7, AF8, AF10, and AF12 respectively. This trend suggests that longer alkyl chains can exploit isoform specific binding for selective SIRT2 inhibition, despite the fact that SIRT1-3 have similar hydrophobic acyl pockets. ${ }^{26} \mathbf{A F 8}$ inhibition of SIRT2 $\left(\mathrm{IC}_{50} 0.061 \pm 0.03 \mu \mathrm{M}\right)$ was the most potent amongst the thiourea inhibitors and comparable to $\mathbf{T M}\left(\mathrm{IC}_{50} 0.034 \pm 0.01\right.$ $\mu \mathrm{M})$.

AF8 was confirmed to work through mechanism-based inhibition of SIRT2. AF8 was incubated with an excess of SIRT2 and NAD ${ }^{+}$and the reaction mixture analyzed by LC-MS. As shown in Fig. 2, the covalent AF8-ADP-ribose intermediate formed by the release of nicotinamide was detected. When $\mathbf{A F 8}$ was removed from the reaction mixture, the intermediate mass was not detected. This result confirmed that $\mathbf{A F 8}$, and likely the other thiourea $\mathbf{A F}$ inhibitors, could covalently react with $\mathrm{NAD}^{+}$. This is consistent with the mass spectrometry detection of the stalled S-alkylamidate intermediate of a previously reported, non-specific lysine-based thiourea sirtuin inhibitor upon incubation with SIRT1. ${ }^{18}$

\section{AF8 and AF10 demonstrated cytotoxicity against human colon, lung, breast, and pancreatic cancer cell lines.}

The thiourea modification and shorter alkyl chains of compounds AF10 and AF8 were predicted to improve solubility as $\mathbf{T M}$ had a calculated cLogP value of 8.8 while the thiourea analogues AF10 and AF8 had calculated cLogP values of 7.04 and 6.13 respectively (Table 1). Thus, the lower cLogP values suggest that AF8 and AF10 may have improved solubility while still maintaining reasonable selectivity and potency for SIRT2. Because of this, AF8 and AF10 were tested for possible anticancer activity amongst various cell lines.

As shown in Table. 2, toxicity was observed in all cancer lines upon treatment with AF8, AF10, and TM. None of the inhibitors were toxic to noncancerous HME1 epithelial cells. In a normal colon cell line, $\mathrm{CCD} 841 \mathrm{CoN}$, the $\mathrm{GI}_{50}$ values of $\mathbf{A F 8}$ and $\mathbf{A F 1 0}$ were also higher in general than those in the cancer cell lines tested. These observations suggested that, while there is variation, cancer cells could rely more on SIRT2-driven pathways for survival and growth. AF10 was the most potent inhibitor and was approximately two-fold more potent than TM in MCF7, MDA-MB-231, A549, SW948, and HCT116 cells (Table 2). AF8 was comparable to TM in most cell lines except the pancreatic BxPC-3 cell line which showed little inhibition by AF8. Both AF8 and AF10 were twice as potent in the colorectal HCT116 cell line as compared to TM (Table 2). AF8 demonstrated minimal inhibition of noncancerous colon cell line CCD $841 \mathrm{CoN}$, suggesting that $\mathbf{A F 8}$ could be used to selectively target cancerous colon cells. Consistent with its increased potency, AF10 showed higher toxicity in CCD $841 \mathrm{CoN}$ cells, which indicated it may have a lower therapeutic index (Table 2).

\section{AF8, AF10, and TM inhibited the anchorage independent growth of HCT116 cells.}

The ability of cancer cells to survive and proliferate without adhesion to an extracellular matrix is one of the hallmarks of oncogenic transformation. ${ }^{27-28}$ To examine anchorage independent growth, HCT116 cells were suspended in a soft agar matrix and incubated until 
colony growth was observed. ${ }^{29}$ Slightly less overall growth was observed in the TM treated group, likely due to a smaller number of cells seeded per well. Treatment with AF8 and AF10 potently inhibited colony formation with $\mathrm{GI}_{50}$ values of 7.4 and $7.0 \mu \mathrm{M}$ respectively while $\mathbf{T M}$ had a weaker effect with a $\mathrm{GI}_{50}$ value of $16.7 \mu \mathrm{M}$ (Fig. 3). The potency of the compounds in the soft agar colony formation assay shows that they can inhibit anchorage independent growth better than normal 2D growth (cytotoxicity assay described in the previous section), suggesting that SIRT2 inhibitors preferentially target the transformed phenotype of cancer cells. This is also consistent with the fact that the inhibitors exhibit less toxicity towards noncancerous cells in the 2D growth assay shown in Table 2.

\section{AF8 and AF10 inhibit SIRT2 but not SIRT1 in cells.}

We next sought to confirm that AF8 and AF10 could selectively inhibit SIRT2 deacetylase activity in cells. Compounds $\mathbf{C 3}, \mathbf{C 5}$, and $\mathbf{C 1 0}$ were also tested to determine if our in vitro sirtuin inhibition assay correlated with SIRT2 inhibition in cells. We monitored a-tubulin acetylation as a readout for SIRT2 inhibition as a-tubulin is a well-known SIRT2 deacetylation substrate. ${ }^{30}$ HCT116 cells were incubated with DMSO alone (control) or varying concentrations of inhibitor for six hours before a-tubulin acetylation was detected by immunofluorescence. As shown in Fig. 4A and Fig. 4C, acetyl a-tubulin levels of HCT116 cells increased upon treatment with TM at 25 and $50 \mu \mathrm{M}$, suggesting the inhibition of SIRT2 activity. AF8 and AF10 treatment at 25 and $50 \mu \mathrm{M}$ also resulted in extensive atubulin hyperacetylation as compared to DMSO. Thus, AF8 and AF10 can also inhibit SIRT2 activity in cells.

SIRT2 inhibition in cells as measured by a-tubulin acetylation was consistent with calculated in vitro SIRT2 inhibition results. As shown in Fig. 4B and Fig. 4D, treatment with 25 or $50 \mu \mathrm{M}$ of $\mathbf{C 3}$ did not increase the acetylation of a-tubulin, corroborating the lack of in vitro SIRT2 inhibition $\left(\mathrm{IC}_{50}>100 \mu \mathrm{M}\right)$. C5 slightly increased a-tubulin acetylation at $25 \mu \mathrm{M}$ and more robustly increased acetylation at $50 \mu \mathrm{M}$, consistent with moderate in vitro SIRT2 inhibition $\left(\mathrm{IC}_{50} 1.0 \mu \mathrm{M}\right)$. C10 increased a-tubulin acetylation at both 25 and $50 \mu \mathrm{M}$, consistent with more potent in vitro SIRT2 inhibition $\left(\mathrm{IC}_{50} 0.036 \mu \mathrm{M}\right)$ (Fig. $4 \mathrm{~B}$ and Fig. $4 \mathrm{D})$. These observations helped to further validate the results from the in vitro sirtuin inhibition assay.

We next tested whether AF8 and AF10 inhibit SIRT1 deacetylase activity in HCT116 cells by monitoring the acetylation of p53, a well-known SIRT1 deacetylation substrate. ${ }^{31} \mathrm{We}$ also tested compounds $\mathbf{C 3}, \mathbf{C 5}$, and $\mathbf{C 1 0}$ to determine if our in vitro SIRT1 inhibition results were consistent with SIRT1 inhibition in cells. HCT116 cells were treated with Trichostatin A, an inhibitor of the zinc-dependent HDACs, and with or without $25 \mu \mathrm{M}$ of our sirtuin inhibitors. The SIRT1-selective inhibitor EX527 increased p53 acetylation, consistent with previous reports (Fig. 5). ${ }^{25,} 32$ TM, AF8, and AF10 did not increase the levels of acetyl p53, indicating that they inhibit SIRT2 but not SIRT1 in cells. Compound $\mathbf{C 3}$ also did not increase the acetylation of $\mathrm{p} 53$, consistent with the lack of in vitro SIRT1 inhibition $\left(\mathrm{IC}_{50}\right.$ $>100 \mu \mathrm{M}$ ). Inhibitors $\mathbf{C 5}$ and $\mathbf{C 1 0}$ moderately increased the acetylation of p53, consistent with the lack of significant SIRT2 selectivity for the compounds (34 and 12-fold respective SIRT2/SIRT1 selectivity). To more closely examine the inhibition of SIRT1 in cells, 
HCT116 cells were co-treated with Trichostatin A and 10-50 $\mu$ M of AF8, AF10, and C10. Compound $\mathbf{C 1 0}$ demonstrated a dose dependent increase in acetyl p53 levels, consistent with in vitro SIRT1 inhibition ( $\mathrm{IC}_{50} 0.45 \mu \mathrm{M}$ ) and lack of significant SIRT2/SIRT1 selectivity (Fig. 5). AF8 did not increase acetyl p53 levels in a dose dependent manner, indicating a lack of SIRT1 inhibition. A very slight increase in acetyl p53 was observed with AF10, but there was no correlation between AF10 concentration and acetyl p53 level, indicating a lack of meaningful SIRT1 inhibition (Fig. 5). This result suggests that the in vitro selectivity of AF8 and AF10 (203 and >1000-fold selectivity respectively), is sufficient to ensure SIRT2 specific inhibition in cells.

\section{AF8 and AF10 significantly reduced tumor growth in a HCTT16 xenograft mice model of colorectal cancer.}

Immunodeficient NOD scid gamma mice (NSG mice) were grafted with HCT116 cells to form tumors and then treated with varying doses of AF8, AF10, or vehicle by intraperitoneal injection over the course of 11 days before the mice were sacrificed and the tumors weighed. As shown in Fig. 6A, AF8 at $25 \mathrm{mg} / \mathrm{kg}$ slightly decreased tumor growth by volume and weight but did not result in a statistically significant difference. AF8 at $100 \mathrm{mg} / \mathrm{kg}$ significantly ( $\mathrm{p}<0.0001$ ) inhibited tumor growth by $80 \%$ as measured by the average tumor volume on the last day of treatment. This was consistent with the significant $(\mathrm{p}=0.0001)$ difference in average tumor weight that demonstrated an inhibition of 78\%. However, AF10 was less potent in this xenograft model. At $100 \mathrm{mg} / \mathrm{kg}$, AF10 inhibited tumor growth significantly $(\mathrm{p}=0.0114)$, but only by $37 \%$ as measured by final tumor volume (Fig. 6B). This was similar to the significant ( $\mathrm{p}=0.0152$ ) tumor inhibition of $49 \%$ as measured by final tumor weight. No significant weight loss was observed in either the AF8 or AF10 treatment groups.

HCT116 xenograft tumor data suggest that thiourea SIRT2 inhibitors presents a possible new therapeutic approach for treating colorectal cancers. Targeted therapies for colorectal cancer are generally more limited to antibodies targeting angiogenesis through VEGF/ VEGFR and growth through EGFR. ${ }^{33-34}$ Such therapies have met moderate success due to the high mutation load found in colorectal cancer, and are frequently less effective against colorectal cancers with constitutively active KRas mutations. ${ }^{35-37}$ The potent inhibition of HCT116 (KRAS ${ }^{\mathrm{G} 13 \mathrm{D}}$ ) xenograft mice tumor growth by AF8 suggests that targeting SIRT2 activity can be a viable therapeutic strategy in colorectal cancers containing a KRAS mutation. Given the broad toxicity of AF8 and AF10 in other cancer cell lines, it is also possible that SIRT2 inhibitors can be useful for treating other type of cancers.

\section{CONCLUSION}

We have developed thiourea mechanism-based inhibitors for SIRT2. Among them, AF8AF12 are highly selective and potent at inhibiting SIRT2 in vitro. Compared with the previous thioamide type inhibitor $\mathbf{T M}$, these thiourea compounds are much easier to synthesize, which allowed us to quickly prepare many compounds. In addition, AF8 is less hydrophobic than TM and thus is more desirable as a therapeutic candidate. 
AF8 and AF10 showed cytotoxicity across a variety of breast, lung, pancreatic, and colorectal cancer cell lines, but showed generally less toxicity in normal cells which suggested that cancer cells could have an increased dependence on SIRT2 activity. AF8 and AF10 also inhibited SIRT2, but not SIRT1 in cells. AF8 at $100 \mathrm{mg} / \mathrm{kg}$ inhibited tumor growth by $80 \%$ in a HCT116 xenograft mouse model. Although in cell culture AF10 is more potent than AF8, in the mouse xenograft model AF8 is better than AF10. This is likely because other properties, such as solubility (AF8 predicted cLogS is -6.5, AF10 predicted cLogS is -7.0), are more important for in vivo efficacy, which should be useful for the future development of new SIRT2 inhibitors as anticancer therapeutic candidates. This represents one of the few studies examining the anticancer effect of SIRT2 inhibition in a mouse xenograft model of tumors. The results further support that SIRT2 inhibition is a promising cancer treatment strategy and that developing new and improved SIRT2 inhibitors is warranted, a task that will be facilitated by the facile synthesis procedure of the thiourea type of SIRT2 inhibitors.

\section{EXPERIMENTAL}

\section{General.}

All reagents were purchased from commercial sources and used without further purification. Reactions were checked for completion by LC-MS and compounds purified through flash chromatography (SiliaFlash Silica Gel, P60). The Cornell University NMR Facility was used to obtain NMR spectra. ${ }^{1} \mathrm{H}$ spectra $\left(500 \mathrm{MHz}\right.$, Chloroform- $d$ ) and ${ }^{13} \mathrm{C}$ NMR spectra (126 $\mathrm{MHz}$, Chloroform- $d$ ) were obtained on a Bruker $500 \mathrm{MHz}$ with cryoprobe. High Resolution Mass Spectrometry was obtained using either an ESI-Orbitrap mass spectrometer or DARTOrbitrap mass spectrometer. The purity of synthesized compounds was confirmed to be $\geq$ $95 \%$ purity by qNMR.

\section{LC-MS System.}

Analysis of reaction mixtures and purified compounds was carried out using a Shimadzu HPLC LC20-AD system connected to a Thermo Scientific LCQ Fleet Ion Trap mass spectrometer, Rugged Ion Max Source (electrospray ionization), reverse phase Phenomenex Kinetex EVO C18 column $(30 \times 2.1 \mathrm{~mm}, 5 \mu \mathrm{M})$. Samples were diluted in water/acetonitrile (1:1) and analyzed using water with $0.1 \%$ acetic acid (Solvent A) and acetonitrile with $0.1 \%$ acetic acid (Solvent B) at a constant flow rate of $0.2 \mathrm{~mL} / \mathrm{min}$, recording UV absorbance at 215 and $260 \mathrm{~nm}$ and positive mode detection of ions.

\section{General Procedure for the synthesis of 1a-b as shown through the preparation of Benzyl tert-butyl (6-((3-hydroxyphenyl)amino)-6-oxohexane-1,5-diyl)(S)-dicarbamate (1a).}

Cbz-L-Lys(Boc)-OH (3 g, $7.89 \mathrm{mmol}, 1 \mathrm{eq})$ was dissolved in dichloromethane (48 mL). To this solution, $\mathrm{N}$-methylmorpholine $(1.39 \mathrm{~mL}, 12.6 \mathrm{mmol}, 1.6 \mathrm{eq})$ and isobutyl chloroformate $(1.43 \mathrm{~mL}, 11.0 \mathrm{mmol}, 1.4 \mathrm{eq})$ were sequentially added and the reaction mixture stirred for 1 $\mathrm{hr}$ at RT. Then, 3-aminophenol (1.022 g, $9.45 \mathrm{mmol}, 1.2 \mathrm{eq}$ ) (or aniline for $\mathbf{1 b}$ ) was added and the reaction mixture stirred for $16 \mathrm{hr}$ at RT. The reaction was checked for completion by TLC (hexanes: ethyl acetate 1:1) and LC-MS. The reaction mixture was further diluted in dichloromethane $(75 \mathrm{~mL})$ and sequentially washed with water $(3 \times 75 \mathrm{~mL})$ and saturated 
brine $(1 \times 75 \mathrm{~mL})$. The organic layer was collected, dried over $\mathrm{Na}_{2} \mathrm{SO}_{4}$, and concentrated by rotary evaporation to yield a viscous, yellow oil. The crude product was purified by silica gel column chromatography (hexanes: ethyl acetate 1:1) to yield 1a as a pale yellow solid in $80 \%$ yield (2.98 g). ${ }^{1} \mathrm{H}$ NMR (500 MHz, Chloroform- $d$ ) $\delta 8.74(\mathrm{~d}, \mathrm{~J}=31.9 \mathrm{~Hz}, 1 \mathrm{H}), 7.45(\mathrm{~s}$, $1 \mathrm{H}), 7.41-7.30(\mathrm{~m}, 5 \mathrm{H}), 7.20-7.08(\mathrm{~m}, 1 \mathrm{H}), 6.87(\mathrm{~s}, 1 \mathrm{H}), 6.64(\mathrm{dd}, \mathrm{J}=8.1,2.3 \mathrm{~Hz}, 1 \mathrm{H})$, $5.93(\mathrm{~d}, \mathrm{~J}=23.4 \mathrm{~Hz}, 1 \mathrm{H}), 5.18-5.02(\mathrm{~m}, 2 \mathrm{H}), 4.75(\mathrm{~s}, 1 \mathrm{H}), 4.37(\mathrm{~d}, \mathrm{~J}=8.4 \mathrm{~Hz}, 1 \mathrm{H}), 3.08$ $(\mathrm{d}, \mathrm{J}=7.0 \mathrm{~Hz}, 2 \mathrm{H}), 1.90(\mathrm{~d}, \mathrm{~J}=13.6 \mathrm{~Hz}, 1 \mathrm{H}), 1.82-1.64(\mathrm{~m}, 1 \mathrm{H}), 1.56-1.32(\mathrm{~m}, 13 \mathrm{H})$. ${ }^{13} \mathrm{C}$ NMR (126 MHz, Chloroform- d) $\delta 170.9,157.0,156.9,156.6,138.5,135.9,129.9$, 128.6, 128.3, 128.2, 112.0, 111.6, 107.4, 79.7, 67.4, 55.9, 39.7, 31.6, 29.5, 28.4, 22.5. HRMS [DART-Orbitrap] $\mathrm{m} / \mathrm{z}$ calculated for $\mathrm{C}_{24} \mathrm{H}_{34} \mathrm{~N}_{3} \mathrm{O}_{4}\left(\left[\mathrm{M}-\mathrm{CO}_{2}+\mathrm{H}\right]^{+}\right) 428.2544$, observed 428.2567.

\section{Benzyl tert-butyl (6-oxo-6-(phenylamino)hexane-1,5-diyl)(S)-dicarbamate (1b).}

White, powdery solid. $94 \%$ yield. ${ }^{1} \mathrm{H}$ NMR $(500 \mathrm{MHz}$, Chloroform- $d$ ) $\delta 8.46(\mathrm{~d}, \mathrm{~J}=47.9$ $\mathrm{Hz}, 1 \mathrm{H}), 7.53$ (d, J = 7.9 Hz, 2H), $7.44-7.29(\mathrm{~m}, 7 \mathrm{H}), 7.17-7.08(\mathrm{~m}, 1 \mathrm{H}), 5.71$ (d, J = 28.3 $\mathrm{Hz}, 1 \mathrm{H}), 5.13(\mathrm{~d}, \mathrm{~J}=3.2 \mathrm{~Hz}, 2 \mathrm{H}), 4.69(\mathrm{~s}, 1 \mathrm{H}), 4.33(\mathrm{~s}, 1 \mathrm{H}), 3.11(\mathrm{~s}, 2 \mathrm{H}), 2.07-1.88(\mathrm{~m}$, 1H), 1.75 (dtd, J = 14.1, 8.6, $5.4 \mathrm{~Hz}, 1 \mathrm{H}), 1.44(\mathrm{~s}, 14 \mathrm{H}) .{ }^{13} \mathrm{C}$ NMR $(126 \mathrm{MHz}$, Chloroformd) $\delta 170.2,156.7,156.4,137.7,136.1,128.9(\mathrm{~d}, \mathrm{~J}=1.2 \mathrm{~Hz}), 128.6,128.3(\mathrm{~d}, \mathrm{~J}=1.4 \mathrm{~Hz})$, $128.1(\mathrm{~d}, \mathrm{~J}=2.7 \mathrm{~Hz}), 124.4,120.0(\mathrm{~d}, \mathrm{~J}=2.4 \mathrm{~Hz}), 79.4,67.3,55.6,39.5,31.6,29.5,28.4$, 22.5, 19.1. HRMS [DART-Orbitrap] $\mathrm{m} / z$ calculated for $\mathrm{C}_{24} \mathrm{H}_{34} \mathrm{~N}_{3} \mathrm{O}_{3}\left(\left[\mathrm{M}-\mathrm{CO}_{2}+\mathrm{H}\right]^{+}\right)$ 412.2595, observed 412.2618.

\section{General Procedure for 2a-b synthesis as shown through the preparation of benzyl (S)-(1- ((3-hydroxyphenyl)amino)-6-isothiocyanato-1-oxohexan-2-yl)carbamate (2a).}

Compound 1a (1g, $2.12 \mathrm{mmol}, 1 \mathrm{eq})$ was dissolved in dichloromethane (14 mL) and trifluoroacetic acid $(7 \mathrm{~mL})$. Reaction was stirred for $1 \mathrm{hr}$ at RT before being concentrated by rotary evaporation to remove the trifluoroacetic acid. The crude mixture was dissolved in tetrahydrofuran ( $21 \mathrm{~mL}$ ) before 1,1'-thiocarbonyl diimidazole (454 mg, $2.54 \mathrm{mmol}, 1.2 \mathrm{eq}$ ) and triethylamine $(0.73 \mathrm{~mL}, 5.3 \mathrm{mmol}, 2.5 \mathrm{eq})$ were sequentially added. The reaction was stirred for $16 \mathrm{hr}$ at RT and then further diluted in ethyl acetate $(100 \mathrm{~mL})$ and washed with water $(3 \times 60 \mathrm{~mL})$ and saturated brine $(1 \times 60 \mathrm{~mL})$. The organic layer was collected, dried over $\mathrm{Na}_{2} \mathrm{SO}_{4}$, and concentrated by rotary evaporation. The crude product was purified by flash chromatography (hexanes: ethyl acetate 2:1) to afford $\mathbf{2 a}$ as a white solid in $68 \%$ yield (594 mg). ${ }^{1} \mathrm{H}$ NMR (500 MHz, Chloroform- $d$ ) $\delta 8.55(\mathrm{~s}, 1 \mathrm{H}), 7.46(\mathrm{~s}, 1 \mathrm{H}), 7.35(\mathrm{~d}, \mathrm{~J}=3.0$ $\mathrm{Hz}, 5 \mathrm{H}), 7.14(\mathrm{t}, \mathrm{J}=8.1 \mathrm{~Hz}, 1 \mathrm{H}), 6.79(\mathrm{~d}, \mathrm{~J}=7.9 \mathrm{~Hz}, 1 \mathrm{H}), 6.64(\mathrm{dd}, \mathrm{J}=8.2,2.3 \mathrm{~Hz}, 1 \mathrm{H})$, $5.65(\mathrm{~d}, \mathrm{~J}=7.2 \mathrm{~Hz}, 1 \mathrm{H}), 5.15(\mathrm{q}, \mathrm{J}=12.2 \mathrm{~Hz}, 2 \mathrm{H}), 4.37(\mathrm{~d}, \mathrm{~J}=8.2 \mathrm{~Hz}, 1 \mathrm{H}), 3.56-3.35(\mathrm{~m}$, $\mathrm{J}=6.9,6.4 \mathrm{~Hz}, 2 \mathrm{H}), 2.01-1.84(\mathrm{~m}, 1 \mathrm{H}), 1.70(\mathrm{tdd}, \mathrm{J}=22.8,11.4,6.1 \mathrm{~Hz}, 2 \mathrm{H}), 1.61-1.35$ $(\mathrm{m}, 2 \mathrm{H}) .{ }^{13} \mathrm{C}$ NMR $(126 \mathrm{MHz}$, Chloroform- $d$ ) $\delta 170.5,156.8,138.2,135.7,130.2,130.0$, 128.6, 128.4, 128.1, 112.2, 111.6, 107.4, 67.7, 55.7, 44.7, 31.4, 29.4, 22.8. HRMS [DARTOrbitrap $] \mathrm{m} / \mathrm{z}$ calculated for $\mathrm{C}_{21} \mathrm{H}_{24} \mathrm{~N}_{3} \mathrm{O}_{4} \mathrm{~S}\left([\mathrm{M}+\mathrm{H}]^{+}\right)$414.1482, observed 414.1507.

\section{Benzyl (S)-(6-isothiocyanato-1-oxo-1-(phenylamino)hexan-2-yl)carbamate (2b).}

White solid, 86\% yield. ${ }^{1} \mathrm{H}$ NMR (500 MHz, Chloroform- $d$ ) $\delta 8.37$ (s, 1H), 7.49 (d, J = 7.9 $\mathrm{Hz}, 2 \mathrm{H}), 7.42-7.25(\mathrm{~m}, 7 \mathrm{H}), 7.13(\mathrm{t}, \mathrm{J}=7.4 \mathrm{~Hz}, 1 \mathrm{H}), 5.60(\mathrm{~d}, \mathrm{~J}=8.8 \mathrm{~Hz}, 1 \mathrm{H}), 5.14(\mathrm{q}, \mathrm{J}=$ 
$12.2 \mathrm{~Hz}, 2 \mathrm{H}), 4.38(\mathrm{q}, \mathrm{J}=7.9,7.3 \mathrm{~Hz}, 1 \mathrm{H}), 3.62-3.40(\mathrm{~m}, \mathrm{~J}=7.0,6.2 \mathrm{~Hz}, 2 \mathrm{H}), 1.98$ (ddt, J $=13.7,10.1,6.1 \mathrm{~Hz}, 1 \mathrm{H}), 1.87-1.63(\mathrm{~m}, 4 \mathrm{H}), 1.55(\mathrm{tdd}, \mathrm{J}=16.2,11.6,7.0 \mathrm{~Hz}, 2 \mathrm{H}) .{ }^{13} \mathrm{C}$ NMR (126 MHz, Chloroform- d) $\delta$ 169.8, 156.7, 137.4, 135.9, 130.4, 129.0, 128.6, 128.4, $128.1,124.7,120.1,67.5,55.4,44.8,31.5,29.5,22.7$. HRMS [DART-Orbitrap] $\mathrm{m} / \mathrm{z}$ calculated for $\mathrm{C}_{21} \mathrm{H}_{24} \mathrm{~N}_{3} \mathrm{O}_{3} \mathrm{~S}\left([\mathrm{M}+\mathrm{H}]^{+}\right)$398.1533, observed 398.1556.

\section{Benzyl (S)-(6-(3-hexylthioureido)-1-oxo-1-(phenylamino)hexan-2-yl)carbamate (AF6).}

White solid, 80\% yield. ${ }^{1} \mathrm{H}$ NMR (500 MHz, Chloroform- $d$ ) $\delta 8.56(\mathrm{~s}, 1 \mathrm{H}), 7.54(\mathrm{~d}, \mathrm{~J}=7.9$ $\mathrm{Hz}, 2 \mathrm{H}), 7.41-7.23(\mathrm{~m}, 7 \mathrm{H}), 7.15-7.08(\mathrm{~m}, 1 \mathrm{H}), 6.09(\mathrm{~s}, 2 \mathrm{H}), 5.76(\mathrm{~d}, \mathrm{~J}=7.8 \mathrm{~Hz}, 1 \mathrm{H})$, $5.20-5.03(\mathrm{~m}, 2 \mathrm{H}), 4.39(\mathrm{t}, \mathrm{J}=7.5 \mathrm{~Hz}, 1 \mathrm{H}), 3.42(\mathrm{~d}, \mathrm{~J}=68.8 \mathrm{~Hz}, 4 \mathrm{H}), 1.94(\mathrm{dt}, \mathrm{J}=14.5$, $7.6 \mathrm{~Hz}, 1 \mathrm{H}), 1.83-1.71(\mathrm{~m}, 1 \mathrm{H}), 1.64(\mathrm{~d}, \mathrm{~J}=7.6 \mathrm{~Hz}, 2 \mathrm{H}), 1.50(\mathrm{dq}, \mathrm{J}=38.3,6.9 \mathrm{~Hz}, 4 \mathrm{H})$, $1.37-1.14(\mathrm{~m}, 7 \mathrm{H}), 0.98-0.72(\mathrm{~m}, 3 \mathrm{H}) .{ }^{13} \mathrm{C}$ NMR $(126 \mathrm{MHz}$, Chloroform- $d$ ) $\delta 181.3$, 170.2, 156.7, 137.5, 136.0, 129.0, 128.6, 128.3, 128.0, 124.7, 120.1, 67.3, 55.3, 43.8, 31.8, 31.4, 29.7, 28.9, 28.2, 26.6, $22.5(\mathrm{~d}, \mathrm{~J}=3.3 \mathrm{~Hz}), 14.0$. HRMS [DART-Orbitrap] $\mathrm{m} / \mathrm{z}$ calculated for $\mathrm{C}_{27} \mathrm{H}_{39} \mathrm{~N}_{4} \mathrm{O}_{3} \mathrm{~S}\left([\mathrm{M}+\mathrm{H}]^{+}\right)$499.2737, observed 499.2766.

\section{Benzyl (S)-(6-(3-heptylthioureido)-1-oxo-1-(phenylamino)hexan-2-yl)carbamate (AF7).}

White solid, $85 \%$ yield. ${ }^{1} \mathrm{H}$ NMR $(500 \mathrm{MHz}$, Chloroform- $d$ ) $\delta 8.51(\mathrm{~s}, 1 \mathrm{H}), 7.54(\mathrm{~d}, \mathrm{~J}=8.0$ $\mathrm{Hz}, 2 \mathrm{H}), 7.41-7.27(\mathrm{~m}, 7 \mathrm{H}), 7.17-7.08(\mathrm{~m}, 1 \mathrm{H}), 6.08(\mathrm{~s}, 2 \mathrm{H}), 5.71(\mathrm{~d}, \mathrm{~J}=8.0 \mathrm{~Hz}, 1 \mathrm{H})$, $5.13(\mathrm{~d}, \mathrm{~J}=5.2 \mathrm{~Hz}, 2 \mathrm{H}), 4.39(\mathrm{~d}, \mathrm{~J}=8.0 \mathrm{~Hz}, 1 \mathrm{H}), 3.43(\mathrm{~d}, \mathrm{~J}=71.3 \mathrm{~Hz}, 3 \mathrm{H}), 1.96(\mathrm{dt}, \mathrm{J}=$ $14.1,7.5 \mathrm{~Hz}, 1 \mathrm{H}), 1.76(\mathrm{dtd}, \mathrm{J}=13.9,8.6,5.8 \mathrm{~Hz}, 1 \mathrm{H}), 1.72-1.60(\mathrm{~m}, 2 \mathrm{H}), 1.60-1.37(\mathrm{~m}$, $4 \mathrm{H}), 1.37-1.12(\mathrm{~m}, 9 \mathrm{H}), 0.94-0.82(\mathrm{~m}, 3 \mathrm{H}) .{ }^{13} \mathrm{C}$ NMR $(126 \mathrm{MHz}$, Chloroform- $d$ ) $\delta$ 181.1, 170.2, 156.7, 137.5, 136.0, 129.0, 128.6, 128.3, 128.0, 124.6, 120.1, 67.3, 55.2, 43.8, 31.8, 31.7, 28.9, 28.3 - $28.0(\mathrm{~m}), 26.9,22.6,22.5,14.1(\mathrm{~d}, \mathrm{~J}=3.0 \mathrm{~Hz})$. HRMS [DARTOrbitrap] $\mathrm{m} / \mathrm{z}$ calculated for $\mathrm{C}_{28} \mathrm{H}_{41} \mathrm{~N}_{4} \mathrm{O}_{3} \mathrm{~S}\left([\mathrm{M}+\mathrm{H}]^{+}\right)$513.2894, observed 513.2930.

\section{General Procedure for $\mathrm{C} 1-\mathrm{C} 12$ and AF6-AF12 synthesis as shown through the preparation of benzyl (S)-(6-(3-octylthioureido)-1-oxo-1-(phenylamino)hexan-2-yl)carbamate (AF8).}

Compound $2 \mathbf{b}$ ( $250 \mathrm{mg}, 0.63 \mathrm{mmol}, 1 \mathrm{eq}$ ) (or 2a for C1-C12) was dissolved in dimethylformamide $(4.2 \mathrm{~mL})$. To this mixture, octylamine $(0.26 \mathrm{~mL}, 1.57 \mathrm{mmol}, 2.5 \mathrm{eq})$ and triethylamine $(0.17 \mathrm{~mL}, 1.25 \mathrm{mmol}, 2 \mathrm{eq})$ were sequentially added and the reaction stirred for $16 \mathrm{hr}$ at RT. The reaction mixture was diluted in dichloromethane $(50 \mathrm{~mL})$ and washed with water $(3 \times 25 \mathrm{~mL})$ and saturated brine $(1 \times 25 \mathrm{~mL})$ before being dried over $\mathrm{Na}_{2} \mathrm{SO}_{4}$ and concentrated by rotary evaporation. The crude mixture was purified by flash chromatography (hexanes: ethyl acetate 2:1) to afford AF8 as a white, crystalline solid in $74 \%$ yield $(247 \mathrm{mg}) .{ }^{1} \mathrm{H}$ NMR $(500 \mathrm{MHz}$, Chloroform- $d$ ) $\delta 8.51(\mathrm{~s}, 1 \mathrm{H}), 7.54(\mathrm{~d}, \mathrm{~J}=8.0 \mathrm{~Hz}$, 2H), $7.43-7.24(\mathrm{~m}, 7 \mathrm{H}), 7.17-7.08(\mathrm{~m}, 1 \mathrm{H}), 6.08(\mathrm{~s}, 2 \mathrm{H}), 5.72(\mathrm{~d}, \mathrm{~J}=8.1 \mathrm{~Hz}, 1 \mathrm{H}), 5.22-$ $5.02(\mathrm{~m}, 2 \mathrm{H}), 4.39(\mathrm{~d}, \mathrm{~J}=8.5 \mathrm{~Hz}, 1 \mathrm{H}), 3.35(\mathrm{~s}, 2 \mathrm{H}), 2.03-1.85(\mathrm{~m}, \mathrm{~J}=6.8 \mathrm{~Hz}, 1 \mathrm{H}), 1.76$ (dtd, J = 13.9, 8.6, $5.7 \mathrm{~Hz}, 1 \mathrm{H}), 1.66(\mathrm{~h}, \mathrm{~J}=6.5 \mathrm{~Hz}, 2 \mathrm{H}), 1.51(\mathrm{dq}, \mathrm{J}=36.6,7.0 \mathrm{~Hz}, 4 \mathrm{H})$, $1.37-1.12(\mathrm{~m}, 11 \mathrm{H}), 0.90(\mathrm{t}, \mathrm{J}=7.0 \mathrm{~Hz}, 3 \mathrm{H}) .{ }^{13} \mathrm{C}$ NMR (126 MHz, Chloroform- $d$ ) $\delta 181.0$, 170.2, 156.7, 137.5, 136.0, 129.0, 128.6, 128.3, 128.0, 124.6, 120.1, 67.3, 55.2, 43.8, 31.8, 29.24, 29.17, 29.0, 28.2, 26.9, 22.6, 22.5, 14.1. HRMS [DART-Orbitrap] $\mathrm{m} / \mathrm{z}$ calculated for $\mathrm{C}_{29} \mathrm{H}_{43} \mathrm{~N}_{4} \mathrm{O}_{3} \mathrm{~S}\left([\mathrm{M}+\mathrm{H}]^{+}\right)$527.3050, observed 527.3078. 


\section{Benzyl (S)-(6-(3-decylthioureido)-1-oxo-1-(phenylamino)hexan-2-yl)carbamate (AF10).}

White solid, 70\% yield. ${ }^{1} \mathrm{H}$ NMR $(500 \mathrm{MHz}$, Chloroform- $d$ ) $\delta 8.51(\mathrm{~s}, 1 \mathrm{H}), 7.54(\mathrm{~d}, \mathrm{~J}=7.9$ $\mathrm{Hz}, 2 \mathrm{H}), 7.42-7.24(\mathrm{~m}, 7 \mathrm{H}), 7.18-7.08(\mathrm{~m}, 1 \mathrm{H}), 6.08(\mathrm{~s}, 2 \mathrm{H}), 5.72(\mathrm{~d}, \mathrm{~J}=8.1 \mathrm{~Hz}, 1 \mathrm{H})$, $5.22-5.04(\mathrm{~m}, 2 \mathrm{H}), 4.39(\mathrm{~d}, \mathrm{~J}=7.9 \mathrm{~Hz}, 1 \mathrm{H}), 3.42(\mathrm{~d}, \mathrm{~J}=76.0 \mathrm{~Hz}, 4 \mathrm{H}), 1.95(\mathrm{dt}, \mathrm{J}=14.2$, $7.5 \mathrm{~Hz}, 1 \mathrm{H}), 1.84-1.71(\mathrm{~m}, 1 \mathrm{H}), 1.55$ (dddq, J = 44.3, 37.4, 14.7, 7.4, $6.9 \mathrm{~Hz}, 5 \mathrm{H}), 1.36-$ $1.14(\mathrm{~m}, 16 \mathrm{H}), 0.90(\mathrm{t}, \mathrm{J}=6.9 \mathrm{~Hz}, 3 \mathrm{H}) .{ }^{13} \mathrm{C}$ NMR $(126 \mathrm{MHz}$, Chloroform- $d$ ) $\delta 181.0,170.2$, $156.7,137.5,136.0,129.0,128.6,128.3,128.0,124.6,120.1,67.3,55.2,44.3,43.8,31.9$, 31.8, 29.5 (d, J = 2.4 Hz), $29.3(\mathrm{~d}, \mathrm{~J}=1.9 \mathrm{~Hz}), 29.0$, 28.2, 26.9, 22.7, 22.5, 14.1. HRMS [DART-Orbitrap] $\mathrm{m} / \mathrm{z}$ calculated for $\mathrm{C}_{31} \mathrm{H}_{47} \mathrm{~N}_{4} \mathrm{O}_{3} \mathrm{~S}\left([\mathrm{M}+\mathrm{H}]^{+}\right)$555.3363, observed 555.3394

\section{Benzyl (S)-(6-(3-dodecylthioureido)-1-oxo-1-(phenylamino)hexan-2-yl)carbamate (AF12).}

White solid, 57\% yield. ${ }^{1} \mathrm{H}$ NMR (500 MHz, Chloroform- $d$ ) $\delta 8.48$ (s, 1H), 7.54 (d, J = 8.0 $\mathrm{Hz}, 2 \mathrm{H}), 7.43-7.24(\mathrm{~m}, 7 \mathrm{H}), 7.17-7.08(\mathrm{~m}, 1 \mathrm{H}), 6.07(\mathrm{~s}, 2 \mathrm{H}), 5.69(\mathrm{~d}, \mathrm{~J}=8.1 \mathrm{~Hz}, 1 \mathrm{H})$, $5.14(\mathrm{~d}, \mathrm{~J}=4.5 \mathrm{~Hz}, 2 \mathrm{H}), 4.38(\mathrm{~d}, \mathrm{~J}=7.9 \mathrm{~Hz}, 1 \mathrm{H}), 3.72-3.21(\mathrm{~m}, 2 \mathrm{H}), 2.04-1.88(\mathrm{~m}, 1 \mathrm{H})$, $1.85-1.72(\mathrm{~m}, 1 \mathrm{H}), 1.67(\mathrm{~h}, \mathrm{~J}=6.7 \mathrm{~Hz}, 1 \mathrm{H}), 1.60-1.39(\mathrm{~m}, 4 \mathrm{H}), 1.37-1.13(\mathrm{~m}, 20 \mathrm{H})$, $0.94-0.86$ (m, 3H). ${ }^{13} \mathrm{C}$ NMR (126 MHz, Chloroform- $d$ ) $\delta$ 181.1, 170.1, 156.7, 137.5, 136.0, 129.0, 128.6, 128.3, 128.0, 124.6, 120.1, 67.4, 55.2, 43.8, 31.9, 31.7, 29.7, 29.64, 29.59, 29.53, 29.4, 29.3, 29.0, 28.2, 28.0, 26.9, 22.7, 22.4, 19.1, 14.1. HRMS [DARTOrbitrap $] \mathrm{m} / \mathrm{z}$ calculated for $\mathrm{C}_{33} \mathrm{H}_{51} \mathrm{~N}_{4} \mathrm{O}_{3} \mathrm{~S}\left([\mathrm{M}+\mathrm{H}]^{+}\right)$583.3676, observed 583.3704.

\section{Benzyl (S)-(1-((3-hydroxyphenyl)amino)-6-(3-methylthioureido)-1-oxohexan-2-yl)carbamate (C1).}

White solid, 48\% yield. ${ }^{1} \mathrm{H}$ NMR (500 MHz, DMSO-d6) $\delta 9.87$ (s, 1H), 9.37 (s, 1H), 7.53 $(\mathrm{d}, \mathrm{J}=7.9 \mathrm{~Hz}, 1 \mathrm{H}), 7.47-7.28(\mathrm{~m}, 5 \mathrm{H}), 7.23-7.14(\mathrm{~m}, 1 \mathrm{H}), 7.07(\mathrm{t}, \mathrm{J}=8.0 \mathrm{~Hz}, 1 \mathrm{H}), 6.99-$ $6.93(\mathrm{~m}, 1 \mathrm{H}), 6.45(\mathrm{dd}, \mathrm{J}=8.0,2.3 \mathrm{~Hz}, 1 \mathrm{H}), 5.04(\mathrm{~s}, 2 \mathrm{H}), 4.11(\mathrm{td}, \mathrm{J}=8.5,5.2 \mathrm{~Hz}, 1 \mathrm{H}), 3.33$ (s, 7H), $2.79(\mathrm{~s}, 3 \mathrm{H}), 1.73-1.55(\mathrm{~m}, 2 \mathrm{H}), 1.55-1.21(\mathrm{~m}, 3 \mathrm{H}) .{ }^{13} \mathrm{C}$ NMR $(126 \mathrm{MHz}$, DMSO- $d 6) \delta 171.4,158.0,156.5,140.4,137.5,129.8,129.4,128.8,128.7,128.3,128.2$, $110.8,110.4,106.8,65.9,55.9,32.1,29.0,23.6$. HRMS [ESI-Orbitrap] $\mathrm{m} / \mathrm{z}$ calculated for $\mathrm{C}_{22} \mathrm{H}_{29} \mathrm{~N}_{4} \mathrm{O}_{4} \mathrm{~S}\left([\mathrm{M}+\mathrm{H}]^{+}\right)$445.1904, observed 445.1908.

\section{Benzyl (S)-(1-((3-hydroxyphenyl)amino)-1-oxo-6-(3-propylthioureido)hexan-2-yl)carbamate (C3).}

White solid, $41 \%$ yield. ${ }^{1} \mathrm{H}$ NMR $(500 \mathrm{MHz}$, Chloroform- $d$ ) $\delta 8.82(\mathrm{~s}, 1 \mathrm{H}), 7.47$ (s, 2H), $7.40(\mathrm{t}, J=2.2 \mathrm{~Hz}, 1 \mathrm{H}), 7.33(\mathrm{~s}, 4 \mathrm{H}), 7.13(\mathrm{t}, J=8.1 \mathrm{~Hz}, 1 \mathrm{H}), 6.93$ (d, $J=8.0 \mathrm{~Hz}, 1 \mathrm{H}), 6.65$ $(\mathrm{dd}, J=8.1,2.3 \mathrm{~Hz}, 1 \mathrm{H}), 6.12(\mathrm{~d}, J=50.5 \mathrm{~Hz}, 1 \mathrm{H}), 5.89(\mathrm{~d}, J=8.0 \mathrm{~Hz}, 1 \mathrm{H}), 5.22-5.00(\mathrm{~m}$, 2H), $4.42(\mathrm{~d}, J=7.7 \mathrm{~Hz}, 1 \mathrm{H}), 3.36$ (d, $J=19.1 \mathrm{~Hz}, 3 \mathrm{H}), 1.86$ (s, 1H), 1.70 (s, $5 \mathrm{H}), 1.56$ (h, $J$ $=7.3 \mathrm{~Hz}, 4 \mathrm{H}), 1.47-1.22(\mathrm{~m}, 1 \mathrm{H}), 0.92(\mathrm{t}, J=7.4 \mathrm{~Hz}, 3 \mathrm{H}) .{ }^{13} \mathrm{C}$ NMR $(126 \mathrm{MHz}$, Chloroform- $d$ ) $\delta 181.2,171.0,156.9,138.3,135.8,130.0,128.6,128.4,128.1,112.3,112.0$, 107.6, 67.5, 55.6, 43.6, 31.9, 29.7, 28.3, 22.6, 22.3, 11.4. HRMS [ESI-Orbitrap] $\mathrm{m} / \mathrm{z}$ calculated for $\mathrm{C}_{24} \mathrm{H}_{33} \mathrm{~N}_{4} \mathrm{O}_{4} \mathrm{~S}\left([\mathrm{M}+\mathrm{H}]^{+}\right)$473.2217, observed 473.2222. 


\section{Benzyl (S)-(1-((3-hydroxyphenyl)amino)-1-oxo-6-(3-pentylthioureido)hexan-2-yl)carbamate} (C5).

White solid, 94\% yield. ${ }^{1} \mathrm{H}$ NMR (500 MHz, DMSO-d6) $\delta 9.87$ (s, 1H), 9.37 (s, 1H), 7.53 $(\mathrm{d}, \mathrm{J}=7.9 \mathrm{~Hz}, 1 \mathrm{H}), 7.37$ (d, J = 5.4 Hz, 4H), $7.35-7.25(\mathrm{~m}, 2 \mathrm{H}), 7.19(\mathrm{q}, \mathrm{J}=2.8,2.2 \mathrm{~Hz}$, $1 \mathrm{H}), 7.07(\mathrm{t}, \mathrm{J}=8.1 \mathrm{~Hz}, 1 \mathrm{H}), 6.99-6.93(\mathrm{~m}, 1 \mathrm{H}), 6.45(\mathrm{dd}, \mathrm{J}=8.1,2.3 \mathrm{~Hz}, 1 \mathrm{H}), 5.04(\mathrm{~s}$, 2H), $4.11(\mathrm{td}, \mathrm{J}=8.6,5.3 \mathrm{~Hz}, 1 \mathrm{H}), 3.33(\mathrm{~s}, 10 \mathrm{H}), 1.63(\mathrm{ddd}, \mathrm{J}=18.2,9.4,4.4 \mathrm{~Hz}, 1 \mathrm{H}), 1.45$ (p, J = 7.2 Hz, 3H), $1.41-1.16(\mathrm{~m}, 5 \mathrm{H}), 0.87(\mathrm{t}, \mathrm{J}=7.1 \mathrm{~Hz}, 3 \mathrm{H}) .{ }^{13} \mathrm{C} \mathrm{NMR}(126 \mathrm{MHz}$, DMSO- $d 6) \delta 171.4,158.0,156.5,140.4,137.5,129.8,128.8,128.3,128.2,110.8,110.4$, 106.8, 65.9, 55.9, 32.1, 29.1, 28.9, 23.6, 22.4, 14.4. HRMS [ESI-Orbitrap] $\mathrm{m} / \mathrm{z}$ calculated for $\mathrm{C}_{26} \mathrm{H}_{37} \mathrm{~N}_{4} \mathrm{O}_{4} \mathrm{~S}\left([\mathrm{M}+\mathrm{H}]^{+}\right)$501.2530, observed 501.2532.

\section{Benzyl (S)-(1-((3-hydroxyphenyl)amino)-6-(3-octylthioureido)-1-oxohexan-2-yl)carbamate (C8).}

White solid, 79\% yield. ${ }^{1} \mathrm{H}$ NMR $(500 \mathrm{MHz}$, Chloroform- $d$ ) $\delta 9.07$ (s, 1H), $8.18(\mathrm{~s}, 1 \mathrm{H})$, 7.39 (s, 1H), 7.29 (p, J = 6.8, 5.7 Hz, 5H), $7.05(\mathrm{t}, \mathrm{J}=8.0 \mathrm{~Hz}, 1 \mathrm{H}), 6.89(\mathrm{~d}, \mathrm{~J}=8.0 \mathrm{~Hz}, 1 \mathrm{H})$, $6.71-6.55(\mathrm{~m}, 1 \mathrm{H}), 6.55-6.19(\mathrm{~m}, 2 \mathrm{H}), 6.14(\mathrm{~d}, \mathrm{~J}=7.9 \mathrm{~Hz}, 1 \mathrm{H}), 5.21-4.87(\mathrm{~m}, 2 \mathrm{H}), 4.39$ $(\mathrm{q}, \mathrm{J}=7.3 \mathrm{~Hz}, 1 \mathrm{H}), 3.71-2.98(\mathrm{~m}, 4 \mathrm{H}), 2.58(\mathrm{~s}, 1 \mathrm{H}), 1.78(\mathrm{~d}, \mathrm{~J}=12.0 \mathrm{~Hz}, 1 \mathrm{H}), 1.71-1.57$ $(\mathrm{m}, 1 \mathrm{H}), 1.48(\mathrm{dt}, \mathrm{J}=19.7,8.5 \mathrm{~Hz}, 3 \mathrm{H}), 1.39-1.04(\mathrm{~m}, 14 \mathrm{H}), 0.88(\mathrm{t}, \mathrm{J}=7.0 \mathrm{~Hz}, 3 \mathrm{H}) .{ }^{13} \mathrm{C}$ NMR (126 MHz, Chloroform-d) $\delta$ 180.9, 171.4, 156.9, 138.3, 135.8, 129.9, 128.6, 128.3, 128.0, 112.3, 112.0, 107.8, 67.4, 55.7, $44.2(\mathrm{~d}, \mathrm{~J}=89.0 \mathrm{~Hz}), 32.0,31.8,29.7,29.3,29.2$, 29.1, 28.3, 26.9, 22.7, 22.6, 14.1. HRMS [ESI-Orbitrap] $\mathrm{m} / \mathrm{z}$ calculated for $\mathrm{C}_{29} \mathrm{H}_{43} \mathrm{~N}_{4} \mathrm{O}_{4} \mathrm{~S}$ $\left([\mathrm{M}+\mathrm{H}]^{+}\right)$543.3000, observed 543.3004.

\section{Benzyl (S)-(6-(3-decylthioureido)-1-((3-hydroxyphenyl)amino)-1-oxohexan-2-yl)carbamate (C10).}

White solid, 80\% yield. ${ }^{1} \mathrm{H}$ NMR (500 MHz, Chloroform- $d$ ) $\delta 9.04(\mathrm{~s}, 1 \mathrm{H}), 8.09(\mathrm{~s}, 1 \mathrm{H})$, $7.39(\mathrm{~s}, 1 \mathrm{H}), 7.29(\mathrm{~s}, 5 \mathrm{H}), 7.06(\mathrm{t}, \mathrm{J}=8.1 \mathrm{~Hz}, 1 \mathrm{H}), 6.90(\mathrm{~d}, \mathrm{~J}=8.0 \mathrm{~Hz}, 1 \mathrm{H}), 6.68-6.54(\mathrm{~m}$, $1 \mathrm{H}), 6.29(\mathrm{~d}, \mathrm{~J}=69.3 \mathrm{~Hz}, 2 \mathrm{H}), 6.10(\mathrm{~d}, \mathrm{~J}=7.9 \mathrm{~Hz}, 1 \mathrm{H}), 5.21-4.88(\mathrm{~m}, 2 \mathrm{H}), 4.40(\mathrm{q}, \mathrm{J}=7.4$ $\mathrm{Hz}, 1 \mathrm{H}), 3.60-3.01(\mathrm{~m}, 4 \mathrm{H}), 2.42(\mathrm{~s}, 1 \mathrm{H}), 1.78(\mathrm{~s}, 1 \mathrm{H}), 1.71-1.57(\mathrm{~m}, 1 \mathrm{H}), 1.49$ (dt, J = 21.7, 7.2 Hz, 4H), 1.26 (d, J = 5.6 Hz, 15H), 0.89 (t, J = 7.0 Hz, 3H). ${ }^{13} \mathrm{C}$ NMR $(126 \mathrm{MHz}$, Chloroform- $d$ ) $\delta 180.9,171.4,156.9,138.3,135.8,130.0,128.6,128.3,128.0,112.3,112.0$, 107.8, 67.4, 55.7, 44.2 (d, J = 82.2 Hz), 32.0, 31.9, 29.6, 29.4, 29.3, 29.1, 28.4, 27.0, 22.8, 22.7, 14.1. HRMS [ESI-Orbitrap] $\mathrm{m} / z$ calculated for $\mathrm{C}_{31} \mathrm{H}_{47} \mathrm{~N}_{4} \mathrm{O}_{4} \mathrm{~S}\left([\mathrm{M}+\mathrm{H}]^{+}\right)$571.3313, observed 571.3311.

\section{Benzyl (S)-(6-(3-dodecylthioureido)-1-((3-hydroxyphenyl)amino)-1-oxohexan-2 yl)carbamate (C12).}

White solid, 82\% yield. ${ }^{1} \mathrm{H}$ NMR (500 MHz, Chloroform- $d$ ) $\delta 9.01(\mathrm{~s}, 1 \mathrm{H}), 8.00(\mathrm{~d}, \mathrm{~J}=8.0$ $\mathrm{Hz}, 1 \mathrm{H}), 7.39(\mathrm{~s}, 1 \mathrm{H}), 7.30(\mathrm{~s}, 5 \mathrm{H}), 7.08(\mathrm{t}, \mathrm{J}=8.1 \mathrm{~Hz}, 1 \mathrm{H}), 6.91(\mathrm{~d}, \mathrm{~J}=8.0 \mathrm{~Hz}, 1 \mathrm{H}), 6.62$ $(\mathrm{dd}, \mathrm{J}=8.0,2.2 \mathrm{~Hz}, 1 \mathrm{H}), 6.54-6.10(\mathrm{~m}, 2 \mathrm{H}), 6.06(\mathrm{~d}, \mathrm{~J}=7.9 \mathrm{~Hz}, 1 \mathrm{H}), 5.20-4.92(\mathrm{~m}, 2 \mathrm{H})$, 4.40 (q, J = 7.4 Hz, 1H), $3.66-3.01(\mathrm{~m}, 4 \mathrm{H}), 2.20(\mathrm{~s}, 1 \mathrm{H}), 1.98-1.72(\mathrm{~m}, 1 \mathrm{H}), 1.66(\mathrm{~d}, \mathrm{~J}=$ $11.1 \mathrm{~Hz}, 1 \mathrm{H}), 1.50(\mathrm{dt}, \mathrm{J}=16.3,7.7 \mathrm{~Hz}, 4 \mathrm{H}), 1.42-1.06(\mathrm{~m}, 20 \mathrm{H}), 0.90(\mathrm{t}, \mathrm{J}=6.9 \mathrm{~Hz}, 3 \mathrm{H})$. ${ }^{13} \mathrm{C}$ NMR (126 MHz, Chloroform- d) $\delta$ 181.0, 171.3, 156.9, 138.3, 135.8, 130.0, 128.6, 128.3, 128.0, 112.3, 112.0, 107.7, 67.5, 55.7, 44.2 (d, J = 103.5 Hz), 32.0, 31.9, 29.69, 
29.67, 29.64, 29.59, 29.4 (d, J = 1.4 Hz), 29.1, 28.3, 27.0, 22.7, 14.2. HRMS [ESI-Orbitrap] $\mathrm{m} / z$ calculated for $\mathrm{C}_{33} \mathrm{H}_{51} \mathrm{~N}_{4} \mathrm{O}_{4} \mathrm{~S}\left([\mathrm{M}+\mathrm{H}]^{+}\right)$599.3626, observed 599.3625.

\section{Sirtuin Purification.}

Human SIRT1-3 were all expressed and purified as previously reported. ${ }^{10}$

\section{Enzyme IC 50 Assay.}

Inhibitors were stored at $-20^{\circ} \mathrm{C}$ as stock solutions in DMSO $(20 \mathrm{mM}-50 \mathrm{mM})$ and further serial dilutions were prepared on the day of the assay. Inhibitors were tested in duplicate at final concentrations ranging from $0.002-417 \mu \mathrm{M}$ with $\mathrm{DMSO}$ as control. At $0{ }^{\circ} \mathrm{C}$, sirtuins were diluted in the reaction buffer ( $20 \mathrm{mM}$ Tris, $1 \mathrm{mM} \mathrm{NAD}^{+}, 1 \mathrm{mM}$ DTT, pH 8.0) to the final concentration $(0.05 \mu \mathrm{M}$ SIRT1, $0.2 \mu \mathrm{M}$ SIRT2, $0.05 \mu \mathrm{M}$ SIRT3). Inhibitors were added to the appropriate SIRT1-3 reaction mixture and preincubated at $37{ }^{\circ} \mathrm{C}$ for $15 \mathrm{~min}$. Acetyl $\mathrm{H} 3 \mathrm{~K} 9$ peptide ( $10 \mu \mathrm{M}$ final concentration) was added to start the reaction, and the reaction mixture further incubated at $37{ }^{\circ} \mathrm{C}$ until $10-18 \%$ of the peptide was deacetylated ( 3 min for SIRT1, 6 min for SIRT2, and $15 \mathrm{~min}$ for SIRT3). The reaction was quenched by the addition of aqueous acid ( $0.2 \mathrm{M} \mathrm{HCl}, 6 \mathrm{M}$ acetic acid) at an equal volume, followed by vigorous vortexing. Samples were then centrifuged at 17,000 g x $2 \mathrm{~min}$ at RT to pellet the enzyme. The supernatant was then analyzed by analytical HPLC on a Shimadzu LC, Phenomenex Kinetex EVO C18 column $(100 \times 4.60 \mathrm{~mm}, 5 \mu \mathrm{M}, 100 \AA$ 丹 $)$, UV absorbance measurement at $215 \mathrm{~nm}$ and $326 \mathrm{~nm}, 0.1 \%$ trifluoroacetic acid in water (Solvent A), $0.1 \%$ trifluoroacetic acid in acetonitrile (Solvent B), and $0.5 \mathrm{~mL} / \mathrm{min}$ flow rate. The peak areas of deacetylated to acetylated $\mathrm{H} 3 \mathrm{~K} 9$ peptide were used to quantify deacetylase activity. Deacetylase activity was then normalized to the DMSO control, and $\log$ (inhibitor concentration) vs normalized deacetylase activity fitted by nonlinear regression to $\mathrm{Y}=100 /\left(1+10^{\wedge}\left(\left(\mathrm{X}-\log \mathrm{IC}_{50}\right)\right)\right)$ on GraphPad Prism version 6.01.

\section{Cell Cytotoxicity Assay.}

To a flat bottom 96-well plate, 1000 - 3000 cells were seeded into each well and incubated for $20 \mathrm{hr}$ at $37^{\circ} \mathrm{C}$ (1000 cells for HCT-116, 2000 cells for MDA-MB-231, MDA-MB-468, NCI-H23, A549, SW948 and 3000 cells for MCF7, BxPC-3, CCD 841 CoN, and HME1). Inhibitors in varying final concentrations $(1-100 \mu \mathrm{M})$ were added to each well and the cells incubated for 72 hours at $37^{\circ} \mathrm{C}$. Then, $100 \mu \mathrm{L}$ of media was removed from each well and 20 $\mu \mathrm{L}$ of CellTiter-Blue (Promega) was added to each well. The 96-well plate was then incubated for 4 hours at $37{ }^{\circ} \mathrm{C}$ to measure cell viability. The fluorescence of each well (560 $\mathrm{nm}$ excitation/590 nm emission) was measured using a Fluoroskan Ascent FL microplate fluorometer. The fluorescence was normalized to DMSO treated cells, and GraphPad Prism software used to plot the cell viability curves and calculate the $\mathrm{GI}_{50}$ value for each cell line.

\section{Soft Agar Assay.}

HCT116 cells in a $10 \mathrm{~cm}$ dish (70-80\% confluent) were rinsed with phosphate buffered saline (PBS), trypsinized for 1 min, resuspended in media (McCoy's Medium $+10 \%$ Calf Serum), and counted by hemocytometry. To make the solid base layer, a stock $3 \%$ agar solution in water was heated to $42{ }^{\circ} \mathrm{C}$, diluted to $0.6 \%$ in media, and mixed with inhibitors to 
final concentrations of $2.5-50 \mu \mathrm{M}$. To each well in a six well plate, $2 \mathrm{~mL}$ of the base layer was added and allowed to solidify for 1 hour at room temperature. To make the growth layer, the stock $3 \%$ agar solution was diluted to $0.3 \%$ in media and inhibitors were added to final concentrations of $2.5-50 \mu \mathrm{M}$. Then, HCT116 cells were added to the growth layer to a concentration of 500 cells $/ \mathrm{mL}$. In triplicate, $2 \mathrm{~mL}$ of the growth layer containing inhibitor and HCT116 cells was added to each well and incubated at $37^{\circ} \mathrm{C}$. After five days, another 2 $\mathrm{mL}$ of growth layer containing inhibitor was added to each well. After 9 to 11 days, $200 \mu \mathrm{L}$ of nitro blue tetrazolium chloride in water $(2 \mathrm{mg} / \mathrm{mL})$ was added to each well and incubated overnight at $37{ }^{\circ} \mathrm{C}$. The plates were imaged using a ChemiDoc MP Imaging System and colonies were counted with ImageJ software.

\section{Xenograft Mice Study.}

All animals used in this study were handled in accordance with federal and institutional guidelines, under a protocol approved by the Cornell University Institutional Animal Care and Use Committee. Immunodeficient female and male NSG mice were purchased from The Jackson Laboratory. When mice were approximately four to eight weeks old, $1 \times 10^{6}$ HCT116 cells were injected on both sides of the abdomen. The cells were allowed to grow for 3 - 5 days until the tumors were just large enough to be visible and measured. Inhibitors were dissolved in solution (80\% PBS, 10\% DMSO, 10\% Kolliphor EL) to a concentration of $10 \mathrm{mg} / \mathrm{mL}$ before injection into mice. AF8 at $25 \mathrm{mg} / \mathrm{kg}(\mathrm{n}=3)$ and $100 \mathrm{mg} / \mathrm{kg}(\mathrm{n}=4)$, or vehicle ( $\mathrm{n}=4)$, was intraperitoneally injected every day over the course of twelve days. AF10 at $100 \mathrm{mg} / \mathrm{kg}(\mathrm{n}=8)$ or vehicle ( $\mathrm{n}=6)$ was also intraperitoneally injected every day over the course of twelve days. Tumor volume was measured daily and mice were sacrificed on the last day and the tumors extracted and weighed.

\section{Immunofluorescence Microscopy.}

400,000 HCT116 cells were seeded per dish (MatTek $35 \mathrm{~mm}$, No. 1.5 coverslip, $14 \mathrm{~mm}$ glass diameter, poly-D-lysine coated) and incubated for $24 \mathrm{hr}$ at $37^{\circ} \mathrm{C}$. Each well was then treated with DMSO or inhibitor at a final concentration of $50 \mu \mathrm{M}$ and incubated for $6 \mathrm{hr}$ at $37^{\circ} \mathrm{C}$. Cells were fixed in ice cold methanol for $10 \mathrm{~min}$. and rinsed $3 \mathrm{x}$ in detergent containing buffer (Tris-buffered saline or TBS, $0.1 \%$ Tx-100). Cells were blocked in blocking buffer (TBS, $0.1 \% \mathrm{Tx}-100,5 \% \mathrm{BSA}$ ) for $1 \mathrm{hr}$ at RT and then incubated in primary acetyl a-tubulin antibody (Millipore MABT868 1:100 dilution) overnight at $4{ }^{\circ} \mathrm{C}$. Cells were then washed $3 \mathrm{x}$ in detergent containing buffer and incubated with secondary antibody (Cy3-conjugated goat a-mouse, Thermo Fisher A10521, 1:500 dilution) for $1 \mathrm{hr}$ at RT. Cells were rinsed $5 \mathrm{x}$ in detergent containing buffer and mounted overnight at RT (DAPI Fluoromount-G, SouthernBiotech). Cells were imaged using a Zeiss LSM880 inverse laser scanning confocal microscope.

\section{P53 Acetylation Assay and Western Blotting.}

400,000 HCT 116 cells were seeded per well in a six well plate and incubated for $24 \mathrm{hr}$ at $37^{\circ} \mathrm{C}$. Subsequently, each well was co-treated with $400 \mathrm{nM}$ TSA and respective concentration of AF8, AF10, TM, EX527, C3, C5, or C10 for six hours at $37^{\circ} \mathrm{C}$ before cells were collected and lysed in buffer (4\% SDS, $150 \mathrm{mM} \mathrm{NaCl}, 50 \mathrm{mM}$ triethanolamine, 
Universal Nuclease, $\mathrm{pH}$ 7.4). The protein concentrations of cell lysates were calculated using the BCA assay. To evaluate AcP53 (K382) levels, $50 \mu \mathrm{g}$ of lysate was ran on a $12 \%$ SDS-PAGE gel. To check protein loading, $8 \mu \mathrm{g}$ of lysate was also loaded on the same gel. The protein gel was transferred to a PVDF membrane, blocked in buffer (TBS, 5\% BSA, $0.1 \%$ Tween-20) for $1 \mathrm{hr}$ at RT, and incubated overnight at $4^{\circ} \mathrm{C}$ with AcP53 (K382) antibody (CST 2525S), or with $\beta$-actin antibody (SCBT sc-47778) for $1 \mathrm{hr}$ at RT. Membranes were rinsed with TBST $(5 \times 7 \mathrm{~min})$ and incubated with anti-rabbit or anti-mouse secondary antibody (CST 7074S and CST 7076S) for $1 \mathrm{hr}$ at RT. Membranes were rinsed again with TBST (5x, 7 min each) before being incubated with ECL substrate and imaged on a Typhoon FLA 7000.

\section{Cell Culture.}

Cell lines were cultured in DMEM with 10\% FBS (MCF-7, 293T, MDA-MB-231, MDAMB-468, HME1, CCD 841 CoN), RPMI with 10\% FBS (A549, SW948, NCIH23, BxPC-3), McCoy's Media with $10 \%$ Calf Serum (HCT116). Cells were incubated at $37{ }^{\circ} \mathrm{C}$ with $5 \%$ $\mathrm{CO}_{2}$.

\section{Supplementary Material}

Refer to Web version on PubMed Central for supplementary material.

\section{ACKNOWLEDGEMENTS}

A.S.F. thanks Dr. Ying-Ling Chiang for his guidance in organic synthesis.

Funding Sources

The work was supported by funds from HHMI and Cornell University. This work made use of the Cornell University NMR Facility, which is supported, in part, by the NSF through MRI award CHE-1531632

Imaging data was acquired through the Cornell University Biotechnology Resource Center, with NYSTEM (CO29155) and NIH (S10OD018516) funding for the shared Zeiss LSM880 confocal/multiphoton microscope.

\section{ABBREVIATIONS}

$\begin{array}{ll}\text { BSA } & \text { Bovine Serum Albumin } \\ \text { FBS } & \text { Fetal Bovine Serum } \\ \text { LC-MS } & \text { Liquid Chromatography-Mass Spectrometry } \\ \text { HPLC } & \text { High Performance Liquid Chromatography } \\ \text { PBS } & \text { Phosphate Buffered Saline } \\ \text { DMSO } & \text { Dimethyl sulfoxide } \\ \text { NAD } & \text { nicotinamide adenine dinucleotide } \\ \text { TEA } & \text { triethylamine } \\ \text { TSA } & \text { Trichostatin A }\end{array}$


$\begin{array}{ll}\text { TBS } & \text { Tris-Buffered Saline } \\ \text { NEAA } & \text { Non-Essential Amino Acids. }\end{array}$

\section{REFERENCES}

(1). Houtkooper RH; Pirinen E; Auwerx J, Sirtuins as regulators of metabolism and healthspan. Nat. Rev. Mol. Cell Biol 2012, 13, 225. [PubMed: 22395773]

(2). Imai SI; Armstrong CM; Kaeberlein M; Guarente L Transcriptional silencing and longevity protein Sir2 is an NAD-dependent histone deacetylase. Nature 2000, 403, 795-800. [PubMed: 10693811]

(3). Bheda P; Jing H; Wolberger C; Lin H, The substrate specificity of sirtuins. Annu. Rev. Biochem 2016, 85 (1), 405-429. [PubMed: 27088879]

(4). Chang HC; Guarente L, SIRT1 and other sirtuins in metabolism. Trends Endocrinol. Metab 2014, 25 (3), 138-145. [PubMed: 24388149]

(5). Rodriguez RM; Fernandez AF; Fraga MF, Role of sirtuins in stem cell differentiation. Genes Cancer 2013, 4 (3-4), 105-111. [PubMed: 24020001]

(6). Liu PY; Xu N; Malyukova A; Scarlett CJ; Sun YT; Zhang XD; Ling D; Su SP; Nelson C; Chang DK; Koach J; Tee AE; Haber M; Norris MD; Toon C; Rooman I; Xue C; Cheung BB; Kumar S; Marshall GM; Biankin AV; Liu T, The histone deacetylase SIRT2 stabilizes Myc oncoproteins. Cell Death Differ. 2013, 20 (3), 503-514. [PubMed: 23175188]

(7). Song NY; Surh YJ, Janus-faced role of SIRT1 in tumorigenesis. Ann. N. Y. Acad. Sci 2012, 1271 (1), 10-19. [PubMed: 23050959]

(8). Xiangyun Y; Xiaomin N; linping G; Yunhua X; Ziming L; Yongfeng Y; Zhiwei C; Shun L, Desuccinylation of pyruvate kinase M2 by SIRT5 contributes to antioxidant response and tumor growth. Oncotarget 2017, 8 (4), 6984-6993. [PubMed: 28036303]

(9). Kim HS; Vassilopoulos A; Wang RH; Lahusen T; Xiao Z; Xu X; Li C; Veenstra TD; Li B; Yu H; Ji J; Wang XW; Park SH; Cha YI; Gius D; Deng CX, SIRT2 maintains genome integrity and suppresses tumorigenesis through regulating APC/C activity. Cancer cell 2011, 20 (4), 487-499. [PubMed: 22014574]

(10). Jing H; Hu J; He B; Negrón Abril YL; Stupinski J; Weiser K; Carbonaro M; Chiang Y-L; Southard T; Giannakakou P; Weiss RS; Lin H, A SIRT2-selective inhibitor promotes c-Myc oncoprotein degradation and exhibits broad anticancer activity. Cancer Cell 2016, 29 (3), $297-$ 310. [PubMed: 26977881]

(11). Yang MH; Laurent G; Bause AS; Spang R; German N; Haigis MC; Haigis KM, HDAC6 and SIRT2 regulate the acetylation state and oncogenic activity of mutant KRAS. Mol. Cancer Res 2013, 11 (9), 1072-1077. [PubMed: 23723075]

(12). Zhou W; Ni TK; Wronski A; Glass B; Skibinski A; Beck A; Kuperwasser C, The SIRT2 deacetylase stabilizes Slug to control malignancy of basal-like breast cancer. Cell Rep. 2016, 17 (5), 1302-1317. [PubMed: 27783945]

(13). Outeiro TF; Kontopoulos E; Altmann SM; Kufareva I; Strathearn KE; Amore AM; Volk CB; Maxwell MM; Rochet JC; McLean PJ; Young AB; Abagyan R; Feany MB; Hyman BT; Kazantsev AG, Sirtuin 2 inhibitors rescue a-Synuclein-mediated toxicity in models of Parkinson's disease. Science 2007, 317 (5837), 516. [PubMed: 17588900]

(14). Lain S; Hollick JJ; Campbell J; Staples OD; Higgins M; Aoubala M; McCarthy A; Appleyard V; Murray KE; Baker L; Thompson A; Mathers J; Holland SJ; Stark MJR; Pass G; Woods J; Lane DP; Westwood NJ, Discovery, in vivo activity, and mechanism of action of a small-molecule p53 activator. Cancer Cell 2008, 13 (5), 454-463. [PubMed: 18455128]

(15). Rumpf T; Schiedel M; Karaman B; Roessler C; North BJ; Lehotzky A; Oláh J; Ladwein KI; Schmidtkunz K; Gajer M; Pannek M; Steegborn C; Sinclair DA; Gerhardt S; Ovádi J; Schutkowski M; Sippl W; Einsle O; Jung M, Selective Sirt2 inhibition by ligand-induced rearrangement of the active site. Nat. Commun 2015, 6, 6263. [PubMed: 25672491]

(16). Spiegelman NA; Price IR; Jing H; Wang M; Yang M; Cao J; Hong JY; Zhang X; Aramsangtienchai P; Sadhukhan S; Lin H, Direct comparison of SIRT2 inhibitors: potency, 
specificity, activity-dependent inhibition, and on-target anticancer activities. ChemMedChem 2018, 13 (18), 1890-1894. [PubMed: 30058233]

(17). Cen Y; Sauve AA, Transition state of ADP-Ribosylation of acetyllysine catalyzed by Archaeoglobus fulgidus Sir2 determined by kinetic isotope effects and computational approaches. J. Am. Chem. Soc 2010, 132 (35), 12286-12298. [PubMed: 20718419]

(18). Hirsch BM; Hao Y; Li X; Wesdemiotis C; Wang Z; Zheng W, A mechanism-based potent sirtuin inhibitor containing Ne-thiocarbamoyl-lysine (TuAcK). Bioorg. Med. Chem. Lett 2011, 21 (16), 4753-4757. [PubMed: 21752644]

(19). Wang Y; Fung YME; Zhang W; He B; Chung MWH; Jin J; Hu J; Lin H; Hao Q, Deacylation mechanism by SIRT2 revealed in the $1^{\prime}$-SH-2' $-\mathrm{O}-$ Myristoyl intermediate structure. Cell Chem. Biol 2017, 24 (3), 339-345. [PubMed: 28286128]

(20). Madsen AS; Andersen C; Daoud M; Anderson KA; Laursen JS; Chakladar S; Huynh FK; Colaço AR; Backos DS; Fristrup P; Hirschey MD; Olsen CA, Investigating the sensitivity of NAD+dependent sirtuin deacylation activities to NADH. J. Biol. Chem 2016, 291 (13), 7128-7141. [PubMed: 26861872]

(21). Michan S; Sinclair D, Sirtuins in mammals: insights into their biological function. Biochem. J 2007, 404 (1), 1-13. [PubMed: 17447894]

(22). Guan X; Lin P; Knoll E; Chakrabarti R, Mechanism of inhibition of the human sirtuin enzyme SIRT3 by nicotinamide: computational and experimental studies. PLoS ONE 2014, 9 (9), e107729. [PubMed: 25221980]

(23). Avalos JL; Bever KM; Wolberger C, Mechanism of sirtuin inhibition by nicotinamide: altering the NAD+ cosubstrate specificity of a Sir2 enzyme. Mol. Cell 2005, 17 (6), 855-868. [PubMed: 15780941]

(24). Kim BS; Lee C-H; Chang G-E; Cheong E; Shin I, A potent and selective small molecule inhibitor of sirtuin 1 promotes differentiation of pluripotent P19 cells into functional neurons. Sci. Rep 2016, 6, 34324. [PubMed: 27680533]

(25). Solomon JM; Pasupuleti R; Xu L; McDonagh T; Curtis R; DiStefano PS; Huber LJ, Inhibition of SIRT1 catalytic activity increases p53 acetylation but does not alter cell survival following DNA damage. Mol. Cell. Biol 2006, 26 (1), 28-38. [PubMed: 16354677]

(26). Teng YB; Jing H; Aramsangtienchai P; He B; Khan S; Hu J; Lin H; Hao Q, Efficient demyristoylase activity of SIRT2 revealed by kinetic and structural studies. Sci. Rep 2015, 5 , 8529. [PubMed: 25704306]

(27). Paoli P; Giannoni E; Chiarugi P, Anoikis molecular pathways and its role in cancer progression. Biochim. Biophys. Acta 2013, 1833 (12), 3481-3498. [PubMed: 23830918]

(28). Hanahan D; Weinberg RA, The hallmarks of cancer. Cell 2000, 100 (1), 57-70. [PubMed: 10647931]

(29). Patel S; Pine S; Rameshwar P, Noble Agar Assay for Self-Renewal. Protoc. Exch 2013 DOI: 10.1038/protex.2013.021

(30). North BJ; Marshall BL; Borra MT; Denu JM; Verdin E, The human Sir2 ortholog, SIRT2, is an NAD+-dependent tubulin deacetylase. Mol. Cell 2003, 11 (2), 437-444. [PubMed: 12620231]

(31). Vaziri H; Dessain SK; Eaton EN; Imai SI; Frye RA; Pandita TK; Guarente L; Weinberg RA, hSIR2(SIRT1) functions as an NAD-dependent p53 deacetylase. Cell 2001, 107 (2), 149-159. [PubMed: 11672523]

(32). Gertz M; Fischer F; Nguyen GTT; Lakshminarasimhan M; Schutkowski M; Weyand M; Steegborn C, Ex-527 inhibits sirtuins by exploiting their unique NAD+-dependent deacetylation mechanism. Proc. Natl. Acad. Sci 2013, 110 (30), E2772. [PubMed: 23840057]

(33). Moriarity A; O’Sullivan J; Kennedy J; Mehigan B; McCormick P, Current targeted therapies in the treatment of advanced colorectal cancer: a review. Ther. Adv. Med. Oncol 2016, 8 (4), 276 293. [PubMed: 27482287]

(34). El Zouhairi M; Charabaty A; Pishvaian MJ, Molecularly targeted therapy for metastatic colon cancer: proven treatments and promising new agents. Gastrointest. Cancer Res 2011, 4 (1), 15 21. [PubMed: 21464866]

(35). Lièvre A; Bachet JB; Boige V; Cayre A; Le Corre D; Buc E; Ychou M; Bouché O; Landi B; Louvet C; André T; Bibeau F; Diebold MD; Rougier P; Ducreux M; Tomasic G; Emile JF; 
Penault-Llorca F; Laurent-Puig P, KRAS mutations as an independent prognostic factor in patients with advanced colorectal cancer treated with cetuximab. J. Clin. Oncol 2008, 26 (3), 374-379. [PubMed: 18202412]

(36). Hsu H-C; Thiam TK; Lu Y-J; Yeh CY; Tsai WS; You JF; Hung HY; Tsai C-N; Hsu A; Chen H-C; Chen S-J; Yang T-S, Mutations of KRAS/NRAS/BRAF predict cetuximab resistance in metastatic colorectal cancer patients. Oncotarget 2016, 7 (16), 22257-22270. [PubMed: 26989027]

(37). Raponi M; Winkler H; Dracopoli NC, KRAS mutations predict response to EGFR inhibitors. Curr. Opin. Pharmacol 2008, 8 (4), 413-418. [PubMed: 18619559] 


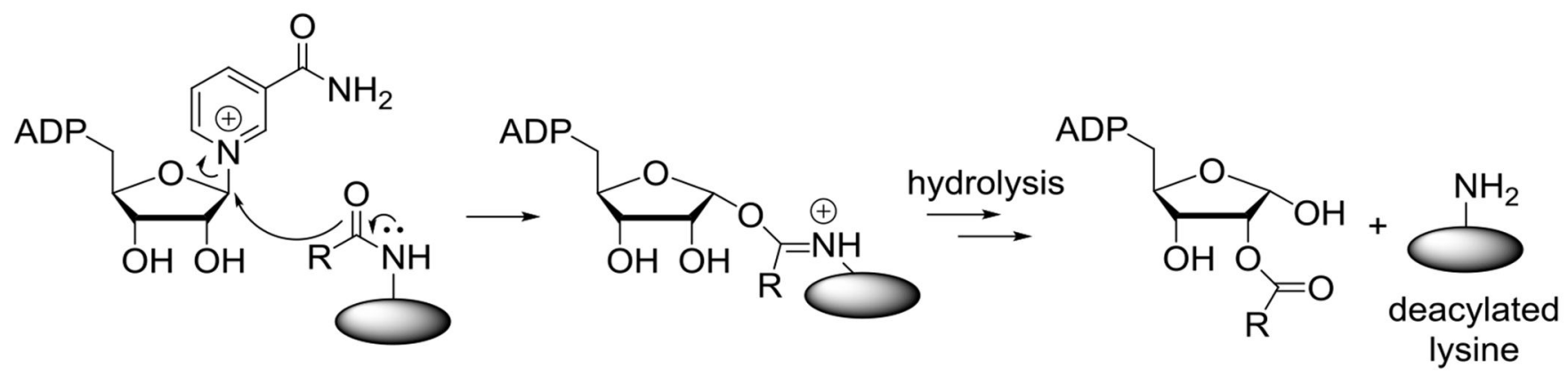

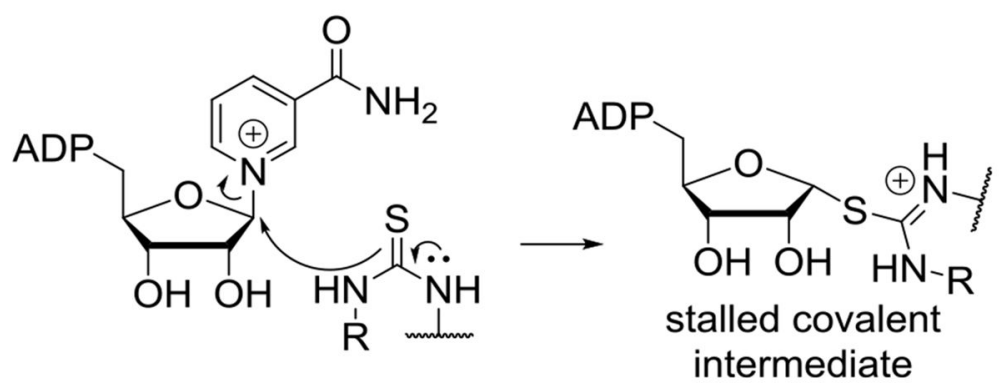

Scheme 1.

Inhibition of sirtuin lysine deacylation by thiourea compounds 


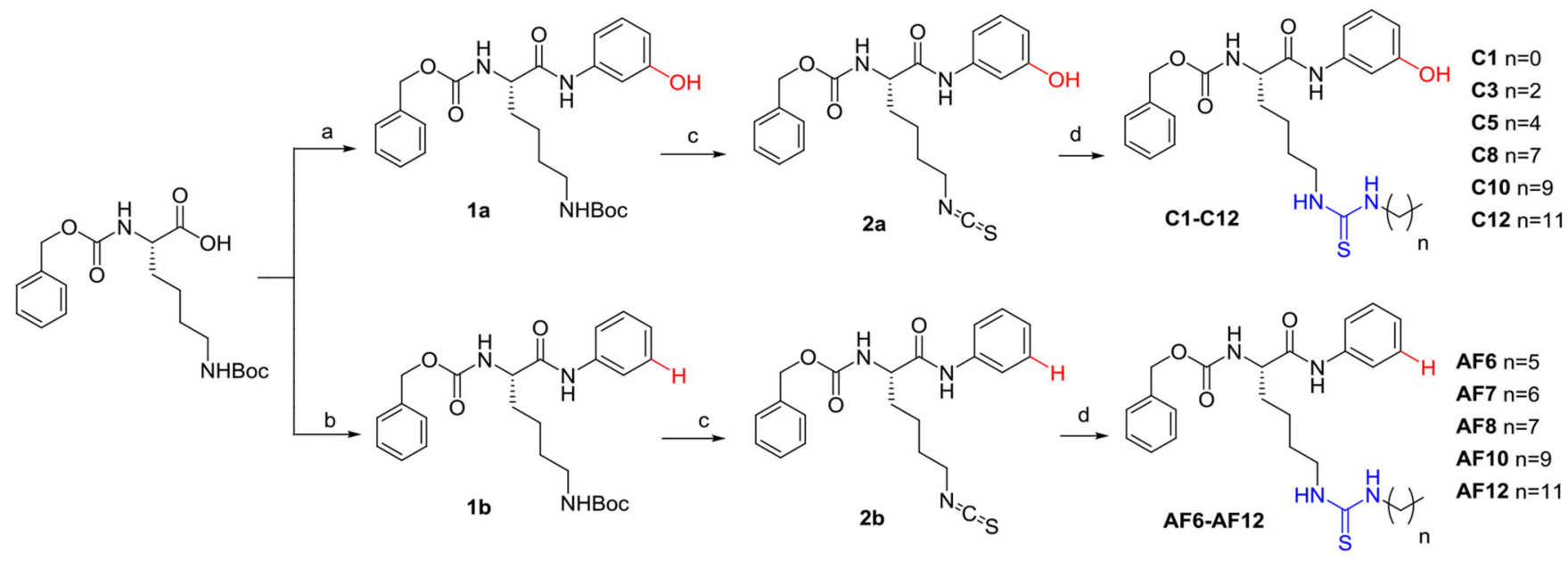

Scheme 2. Synthesis of thiourea compounds with varying chain length ${ }^{a}$

${ }^{a}$ Reactions and conditions: (a) (i) Dichloromethane (DCM), N-methylmorpholine, isobutyl chloroformate, rt, $1 \mathrm{~h}$; (ii) addition of 3-aminophenol, 16 h. (b) (i) DCM, Nmethylmorpholine, isobutyl chloroformate, rt, $1 \mathrm{~h}$; (ii) addition of aniline, $16 \mathrm{~h}$. (c) (i) DCM/ Trifluoroacetic acid, rt, 1 h; (ii) Tetrahydrofuran, triethylamine (TEA), 1,1'thiocarbonyldiimidazole, rt, $16 \mathrm{~h}$. (d) Dimethylformamide, TEA, addition of corresponding primary alkylamine, rt, $16 \mathrm{~h}$. 


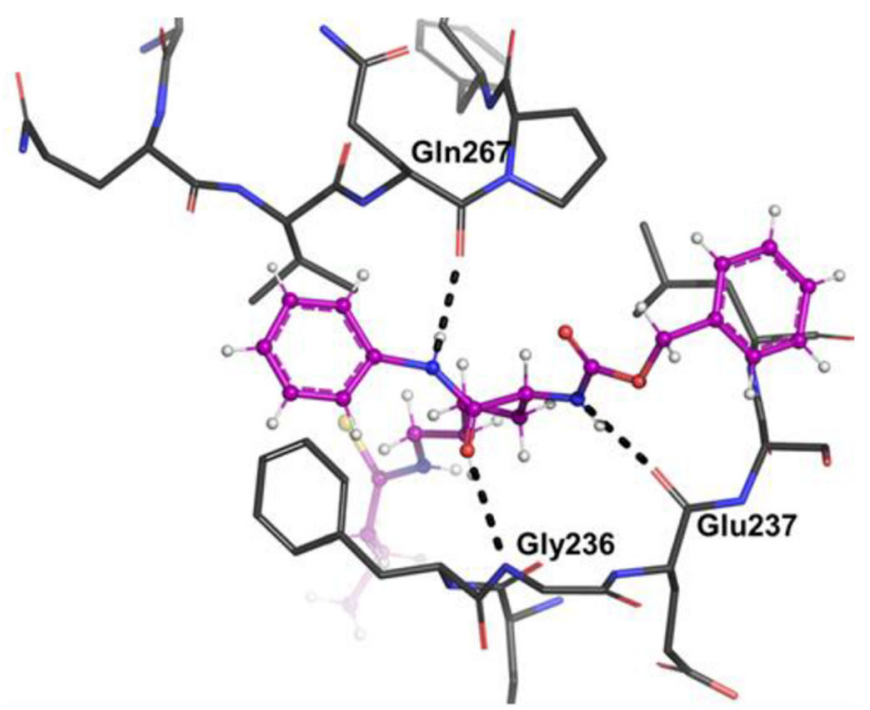

"AF" Inhibitor

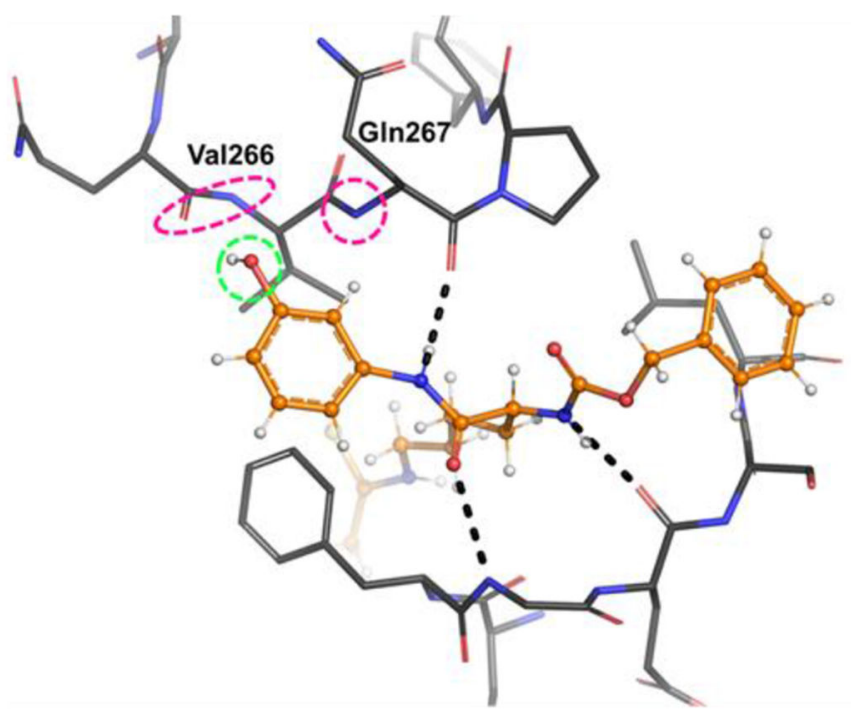

"C" Inhibitor

Figure 1.

The $\mathbf{C}$ class inhibitors modeled into the peptide binding site of SIRT2 (PDB code 4X3O) show additional possible hydrogen bonds as compared to the AF inhibitors. For both classes of inhibitors, hydrogen bonds are predicted to form between the lysine carbonyl and the Gly236 backbone nitrogen, between the N-terminus lysine backbone nitrogen and the Glu237 backbone carbonyl, and between the C-terminus backbone nitrogen and the Gln267 backbone carbonyl. The 3' hydroxyl of the $\mathbf{C}$ class inhibitors (circled in green) could make 
additional hydrogen bonds with the Gln267 backbone nitrogen or the Val266 backbone carbonyl or nitrogen (circled in pink). 
Farooqi et al.

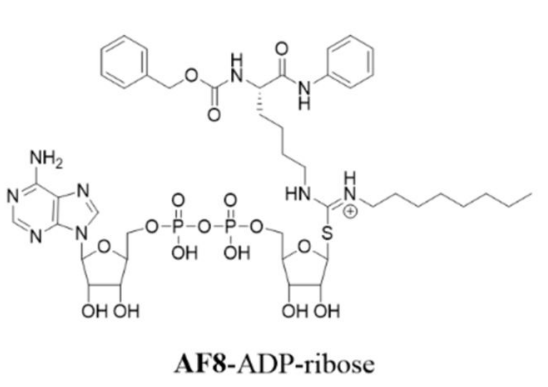

Exact Mass: 1068.37
$1067.5-1068.5 \mathrm{~m} / \mathrm{z}$ trace

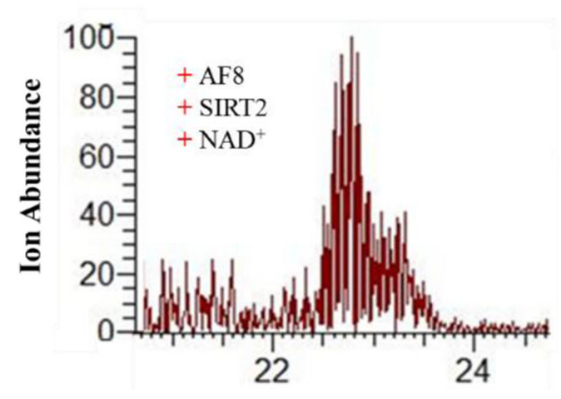

Retention Time (min)
Page 22

$1067.5-1068.5 \mathrm{~m} / \mathrm{z}$ trace

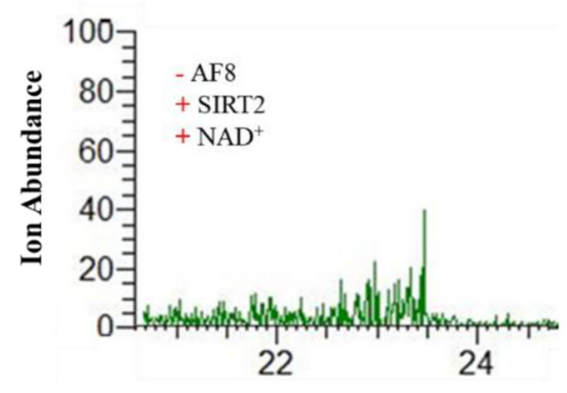

Retention Time (min)

Figure 2.

Detecting the covalent intermediate formed between $\mathbf{A F 8}$ and $\mathrm{NAD}^{+}$in the presence of SIRT2 by liquid chromatography-mass spectrometry (LC-MS). When AF8 was removed from the reaction mixture, the intermediate mass was not detected as shown through the $1067.5-1068.5 \mathrm{~m} / \mathrm{z}$ ion trace. 
DMSO
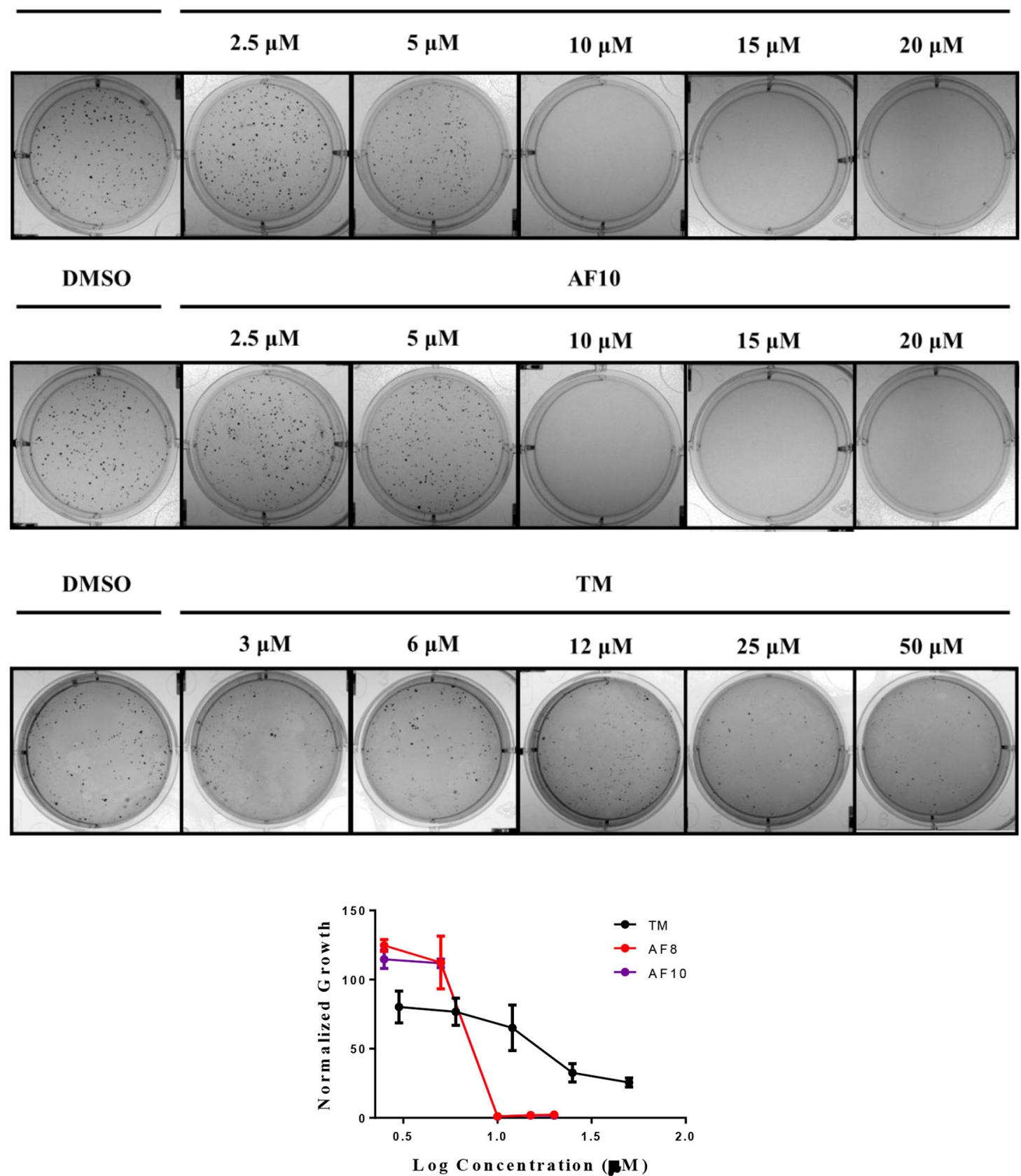

Figure 3.

AF8, AF10, and TM inhibited the anchorage-independent growth of HCT116 cells in a soft agar colony formation assay. At a concentration of $10 \mu \mathrm{M}$ and greater, AF8 and AF10 completely inhibited the growth of HCT116 cells. The $\mathrm{GI}_{50}$ values for AF8 and AF10 were 7.4 and $7.0 \mu \mathrm{M}$ respectively whereas the $\mathrm{GI}_{50}$ for $\mathbf{T M}$ was $16.7 \mu \mathrm{M}$. 
A

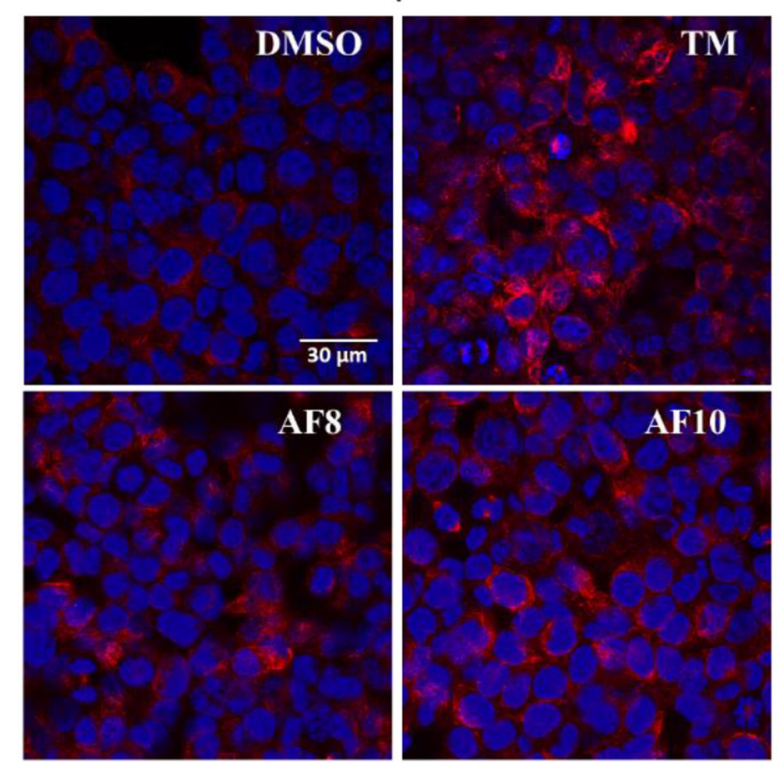

C

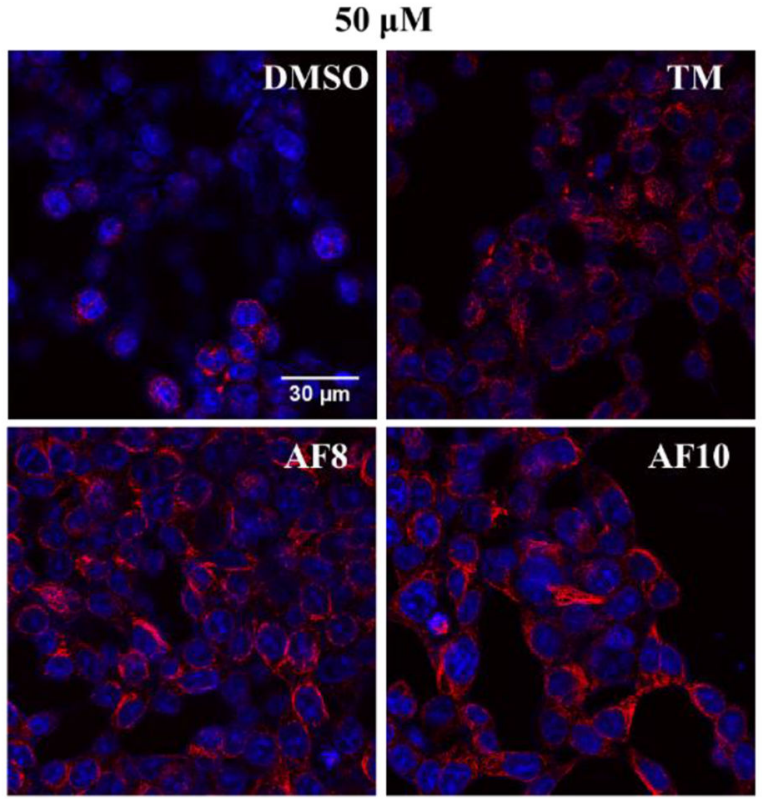

B

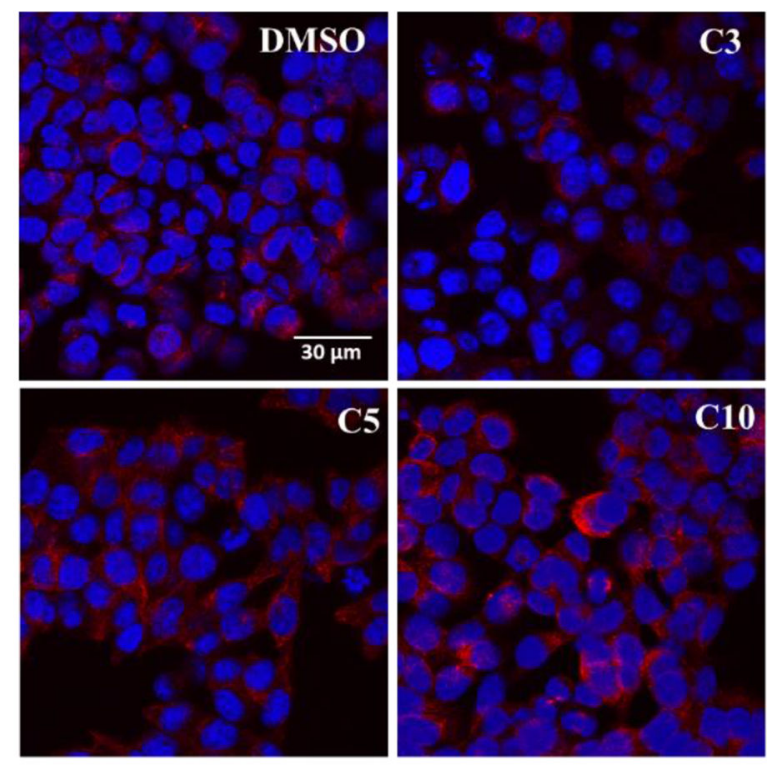

D

$50 \mu \mathrm{M}$

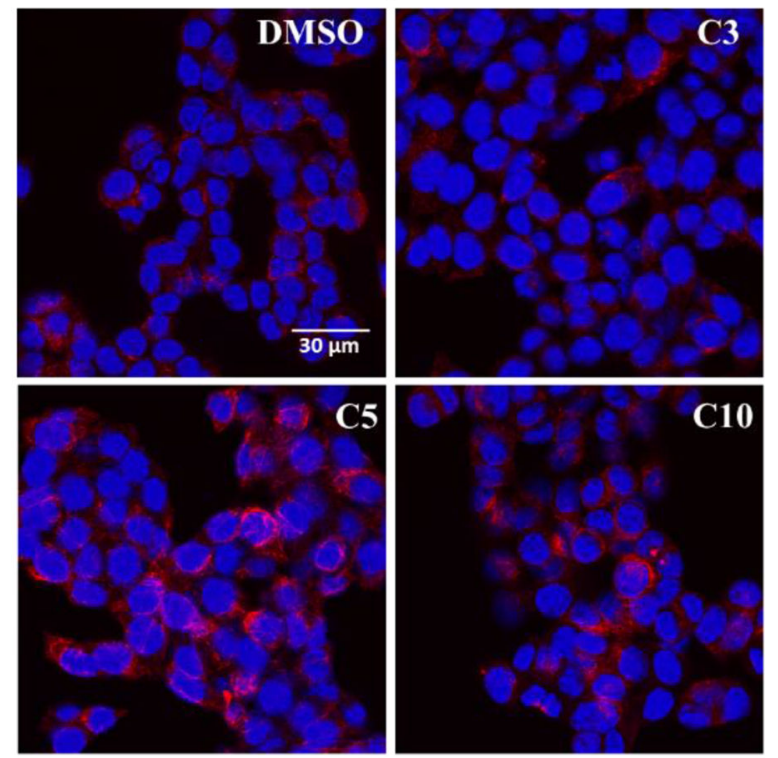

\section{Acetyl $\alpha$-tubulin/DAPI}

Figure 4.

AF8, AF10, TM, C5, and C10 inhibit SIRT2 activity in HCT116 cells as shown through an increase in a-tubulin acetylation. HCT116 cells were incubated with 25 or $50 \mu \mathrm{M}$ of inhibitor for six hours at $37^{\circ} \mathrm{C}$ and a-tubulin acetylation detected by immunofluorescence. (A) At $25 \mu \mathrm{M}, \mathbf{T M}, \mathbf{A F 8}$, and AF10 increased a-tubulin acetylation in HCT116 cells. (B) At $25 \mu \mathrm{M}, \mathbf{C 3}$ did not increase a-tubulin acetylation, C5 slightly increased a-tubulin acetylation, and $\mathbf{C 1 0}$ more strongly increased a-tubulin acetylation. (C) At $50 \mu \mathrm{M}, \mathbf{T M}$, 
AF8, and AF10 also increased a-tubulin acetylation. (D) At $50 \mu \mathrm{M}, \mathbf{C 3}$ did not increase atubulin acetylation, but $\mathbf{C 5}$ and $\mathbf{C 1 0}$ increased a-tubulin acetylation. 

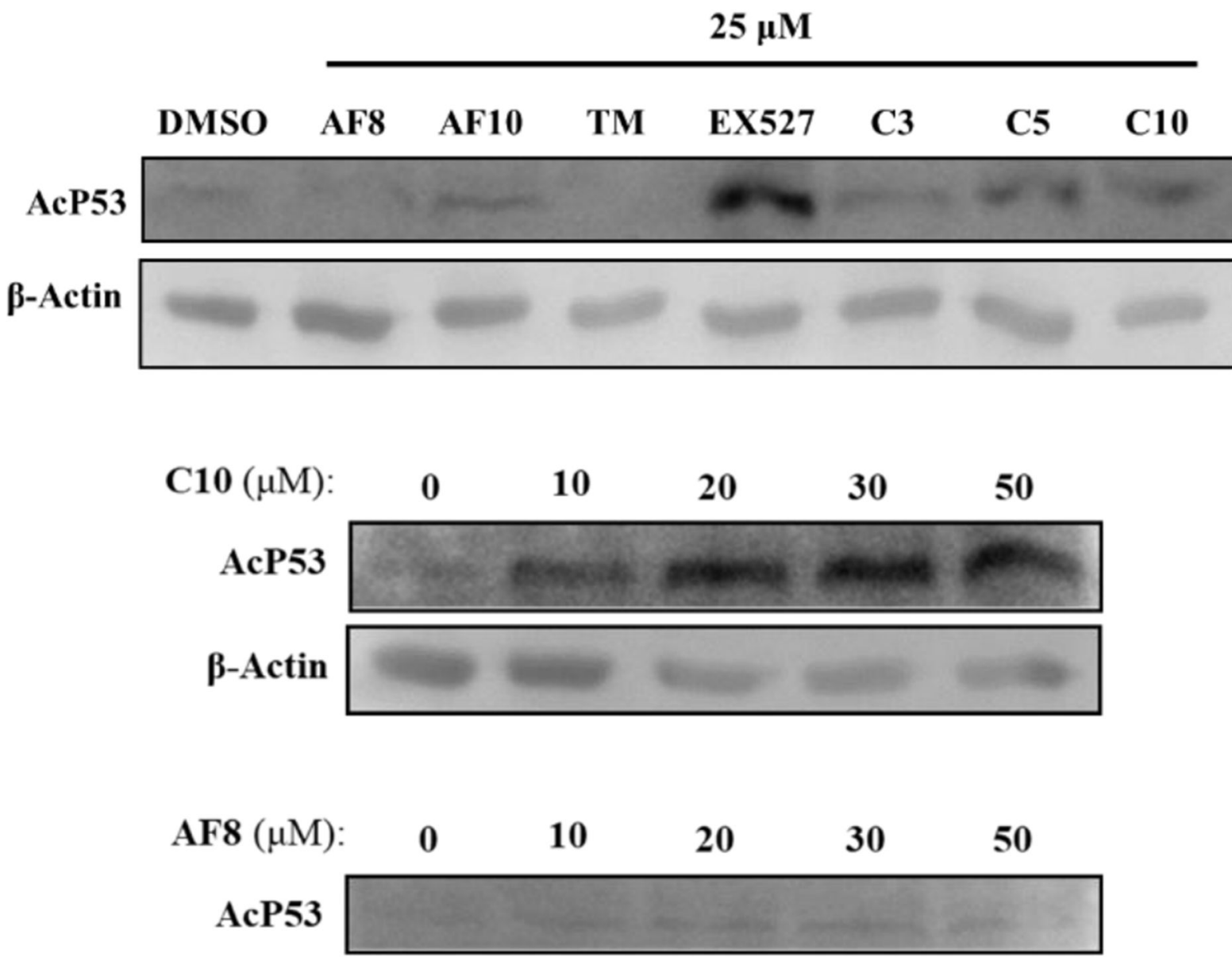

$\beta$-Actin

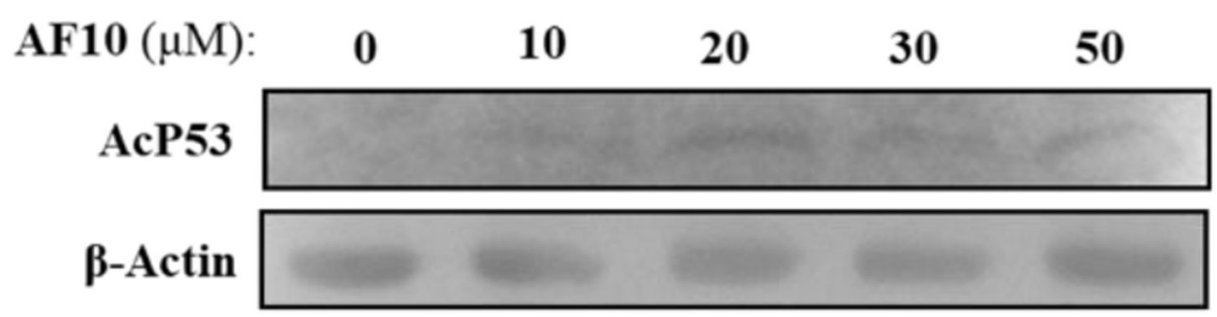

Figure 5.

AF8 and AF10 did not noticeably increase p53 acetylation. HCT116 cells were co-incubated with $400 \mathrm{nM}$ TSA and $25 \mu \mathrm{M}$ of TM, AF8, AF10, C3, C5, C10, and EX527 for 6 hours and p53 K382 acetylation levels analyzed by western blot. Known SIRT1 inhibitor EX527 dramatically increased acetyl p53 levels, while compounds C5 and C10 moderately increased acetyl p53 levels. A dose dependent increase of acetyl p53 was observed upon treatment with C10, but not AF8 and AF10. 
A

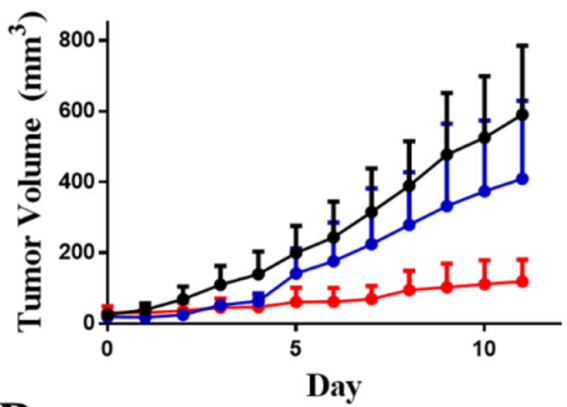

B

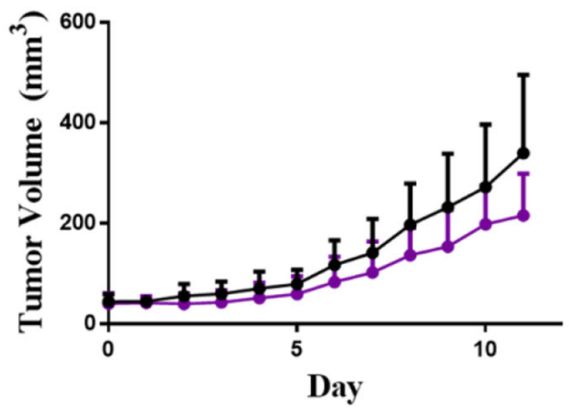

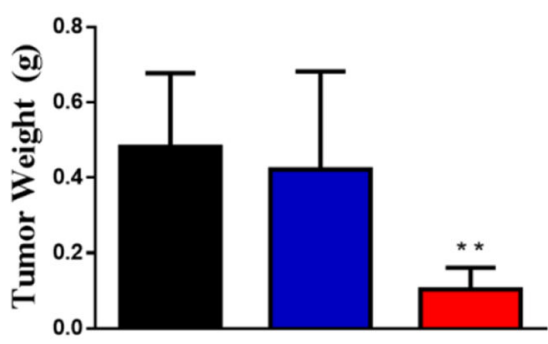
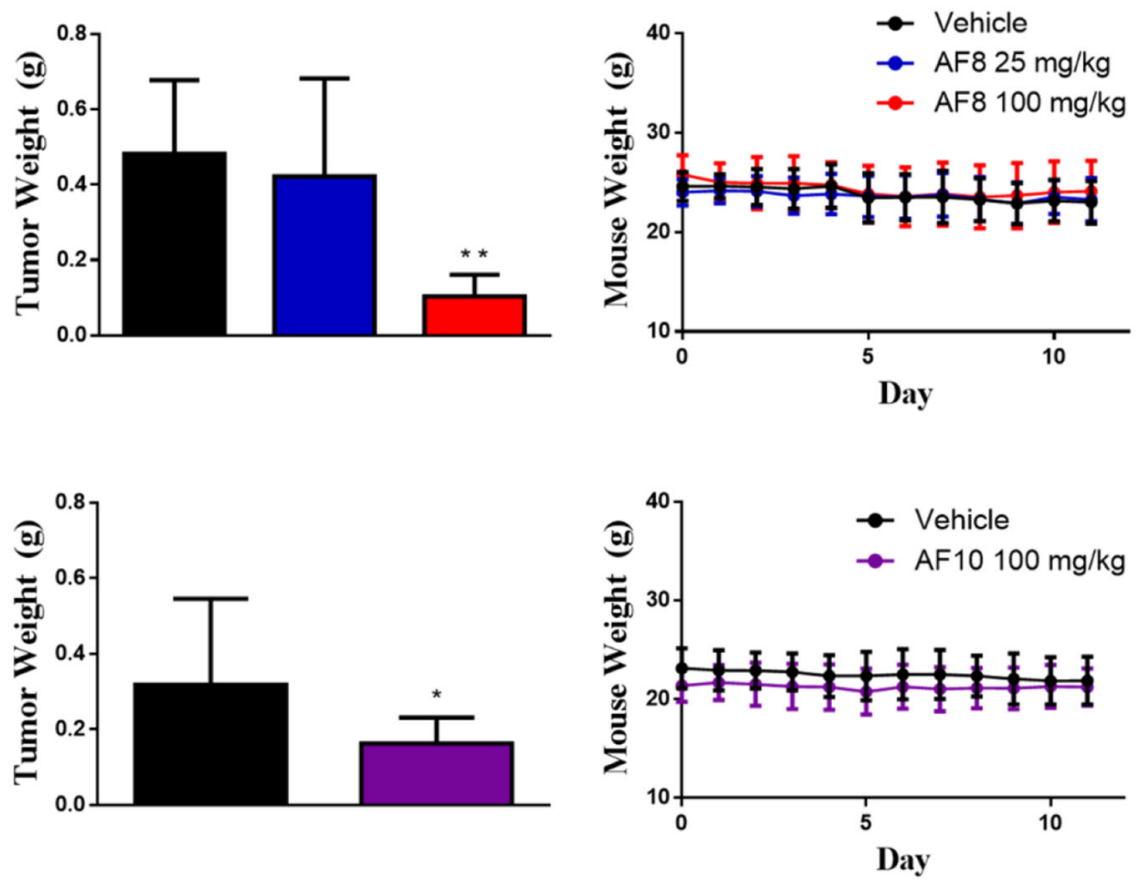

Figure 6.

AF8 and AF10 significantly inhibit tumor growth by volume and weight in a HCT116 xenograft murine model of colorectal cancer. (A) Tumor volume, tumor weight, and mouse body weight for mice treated with vehicle ( $\mathrm{n}=4)$, AF8 $25 \mathrm{mg} / \mathrm{kg}(\mathrm{n}=3), \mathbf{A F 8} 100 \mathrm{mg} / \mathrm{kg}$ ( $\mathrm{n}$ =4). (B) Tumor volume, tumor weight, and mouse body weight for mice treated with vehicle $(\mathrm{n}=6)$ or AF10 $100 \mathrm{mg} / \mathrm{kg}(\mathrm{n}=8)$. Statistical results were analyzed with an unpaired, two tailed t-test. 
Table 1.

In vitro $\mathrm{IC}_{50}$ values of inhibitors for SIRT1-3 and relative selectivity for SIRT2 over SIRT1.

\begin{tabular}{|c|c|c|c|c|c|c|c|}
\hline Compound & $\mathbf{R}^{1}$ & Chain Length & SIRT1 IC $_{50}(\mu \mathrm{M})^{a}$ & $\operatorname{SIRT} \operatorname{IC}_{50}(\mu \mathrm{M})$ & $\operatorname{SIRT3~IC~}_{50}(\mu \mathrm{M})$ & $\begin{array}{c}\text { SIRT2/SIRT1 } \\
\text { Selectivity }\end{array}$ & $C \log \mathrm{P}^{b}$ \\
\hline C1 & $\mathrm{OH}$ & $\mathrm{n}=0$ & $>100$ & $>100$ & $>100$ & NA & 2.65 \\
\hline C3 & $\mathrm{OH}$ & $\mathrm{n}=2$ & $>100$ & $>100$ & $>100$ & NA & 3.52 \\
\hline C5 & $\mathrm{OH}$ & $\mathrm{n}=4$ & $34 \pm 2$ & $1.0 \pm 0.3$ & $>100$ & 34 & 4.42 \\
\hline C8 & $\mathrm{OH}$ & $\mathrm{n}=7$ & $1.0 \pm 0.6$ & $0.12 \pm 0.001$ & $>100$ & 8 & 5.79 \\
\hline C10 & $\mathrm{OH}$ & $\mathrm{n}=9$ & $0.45 \pm 0.1$ & $0.036 \pm 0.0001$ & $>100$ & 12 & 6.7 \\
\hline C12 & $\mathrm{OH}$ & $\mathrm{n}=11$ & $1.0 \pm 0.6$ & $0.060 \pm 0.0005$ & $>100$ & 17 & 7.6 \\
\hline AF6 & $\mathrm{H}$ & $\mathrm{n}=5$ & $30 \pm 11$ & $0.64 \pm 0.02$ & $68 \pm 19$ & 47 & 5.22 \\
\hline AF7 & $\mathrm{H}$ & $\mathrm{n}=6$ & $22 \pm 2$ & $0.16 \pm 0.006$ & $83 \pm 11$ & 137 & 5.68 \\
\hline AF8 & $\mathrm{H}$ & $\mathrm{n}=7$ & $11 \pm 5$ & $0.061 \pm 0.030$ & $51 \pm 0.4$ & 180 & 6.13 \\
\hline AF10 & $\mathrm{H}$ & $\mathrm{n}=9$ & $>200$ & $0.15 \pm 0.06$ & $>200$ & $>1000$ & 7.04 \\
\hline AF12 & $\mathrm{H}$ & $\mathrm{n}=11$ & $>200$ & $0.081 \pm 0.030$ & $>200$ & $>1000$ & 7.95 \\
\hline $\mathbf{T M}$ & NA & NA & $>200$ & $0.034 \pm 0.010$ & $>100$ & $>1000$ & 8.80 \\
\hline Nicotinamide & NA & NA & & $70 \pm 5$ & $76 \pm 30$ & & \\
\hline EX527 & NA & NA & $0.085 \pm 0.01$ & $1.80 \pm 0.03$ & & & \\
\hline
\end{tabular}

${ }^{a}$ In vitro IC50 values were calculated in duplicate using acetylated H3K9 peptide and liquid chromatography. Statistical analysis was done on GraphPad Prism, and reported values include the SEM.

${ }^{b}$ ClogP values computed using DataWarriors software. 
Table 2.

$\mathrm{GI}_{50}$ values of SIRT2 inhibitors across a variety of cell lines.

\begin{tabular}{ccccc}
\hline Cell Line & Type & TM GI $_{\mathbf{5 0}}(\boldsymbol{\mu M})$ & AF8 GI $_{\mathbf{5 0}}(\boldsymbol{\mu M})$ & AF10 GI $_{\mathbf{5 0}}(\boldsymbol{\mu M})$ \\
\hline MCF7 & Breast Cancer & $37.0 \pm 4.5$ & $42.6 \pm 18.5$ & $18.4 \pm 6.0$ \\
MDA-MB-468 & Breast Cancer & $15.7 \pm 2.5$ & $26.1 \pm 6.4$ & $13.4 \pm 1.7$ \\
MDA-MB-231 & Breast Cancer & $42.8 \pm 6.5$ & $27.2 \pm 8.1$ & $14.8 \pm 4.1$ \\
BxPC-3 & Pancreatic Cancer & $13.3 \pm 3.5$ & $72.4 \pm 25.5$ & $24.3 \pm 5.0$ \\
NCI-H23 & Lung Cancer & $16.4 \pm 1.8$ & $35.8 \pm 14.2$ & $15.6 \pm 3.5$ \\
A549 & Lung Cancer & $17.3 \pm 6.0$ & $20.8 \pm 6.9$ & $9.0 \pm 3.9$ \\
SW948 & Colorectal Cancer & $19.2 \pm 3.5$ & $30.0 \pm 8.9$ & $12.8 \pm 3.5$ \\
HCT116 & Colorectal Cancer & $131.6 \pm 54.0$ & $58.9 \pm 26.5$ & $54.4 \pm 12.6$ \\
CCD 841 CoN & Colon Cells & n.d. ${ }^{a}$ & $136.8 \pm 53.5$ & $47.4 \pm 7.0$ \\
HME1 & Epithelial Cells & n.i. ${ }^{b}$ & n.i. & n.i. \\
\hline
\end{tabular}

${ }^{a}$ nd: not determined.

$b_{\text {ni: no inhibition. }}$ 